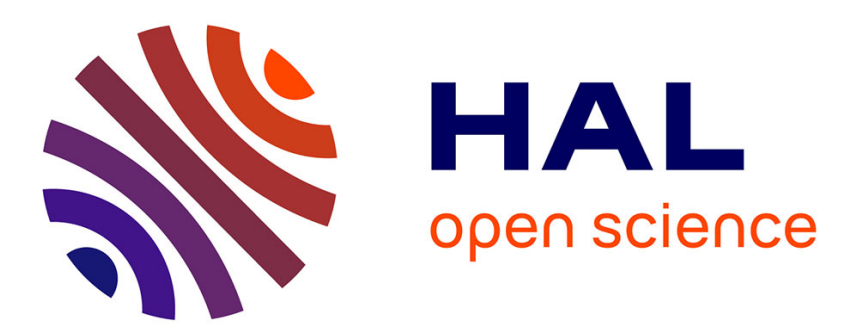

\title{
La place d'Hugues de Saint-Cher dans les débats sur la pluralité des bénéfices (1230-1240)
}

Charles de Miramon

\section{To cite this version:}

Charles de Miramon. La place d'Hugues de Saint-Cher dans les débats sur la pluralité des bénéfices (1230-1240). La place d'Hugues de Saint-Cher dans les débats sur la pluralité des bénéfices (12301240), Mar 2000, Paris, France. pp.341-386, 10.1484/M.BHCMA-EB.3.3093 . halshs-01064210

\section{HAL Id: halshs-01064210 https://shs.hal.science/halshs-01064210}

Submitted on 15 Sep 2014

HAL is a multi-disciplinary open access archive for the deposit and dissemination of scientific research documents, whether they are published or not. The documents may come from teaching and research institutions in France or abroad, or from public or private research centers.
L'archive ouverte pluridisciplinaire HAL, est destinée au dépôt et à la diffusion de documents scientifiques de niveau recherche, publiés ou non, émanant des établissements d'enseignement et de recherche français ou étrangers, des laboratoires publics ou privés. 


\title{
La place D'Hugues de Saint-Cher dans les DÉBATS SUR LA PLURALITÉ DES BÉNÉFICES (I230-I240)
}

\author{
Charles de Miramon"
}

\begin{abstract}
La pluralité des bénéfices : une nouveauté au $\mathrm{xIII}^{e}$ siècle, 5 - Le cumul des revenus ecclésiastiques dans la théologie morale parisienne, 7 - La construction d'une opinion publique sur la question des bénéfices au xiII siècle, 9 - Le basculement de l'opinion publique anglaise, 17 - La simonie dans le Scriptum d'Hugues de Saint-Cher, 18 - Les questions disputées de 1235-1242,19 - La position de l'ordre dominicain sur la pluralité des bénéfices, 23 - La question disputée (A) d'Hugues de Saint-Cher de 1235-1236, 25 - L'évolution de la position d'Hugues de Saint-Cher, 28 Épilogue : le concile de Londres de 1237, 30 - Annexe: Hugues de Saint-Cher était-il un juriste?, 33 - Annexe : Le dossier des textes de la querelle de 1235-1238, 40.
\end{abstract}

$\mathrm{E}^{\mathrm{N}}$ N JUILlet I245, alors que le premier concile de Lyon se termine, Innocent IV craignant une attaque de larmée de Frédéric II, décide de destituer larchevêque Ayméric pour le remplacer par un jeune homme, Philippe de Savoie. Les Savoie, ce sont un peu les «Kennedy » du XIII ${ }^{\mathrm{e}}$ siècle : jeunes, beaux, athlétiques, bien nés, remplis d'ambition et avec une forte propension à mourir jeune ${ }^{1}$. Des hommes qui font chavirer le cœur des dames, faciles en amitié, entrainant sur le champ de bataille leurs chevaliers dans des actions héroïques. Des clercs aussi, des évêques mais plutôt dans le style de Turpin que dans celui de Grégoire le Grand. Alors que le pape fait ses bagages pour se rendre à Cluny, on peut imaginer la conversation qui a lieu en ce moment dans le couvent dominicain de Lyon entre Hugues de Saint-Cher, Henri de Suse et Humbert de Romans ${ }^{2}$. Pour ces trois personnes, la vie professionnelle s'est brusquement accélérée. Hugues a tout juste accédé à la pourpre cardinalice et son disciple Humbert, lancien prieur de Lyon, reprend son poste de provincial de France;

\footnotetext{
"Initialement paru dans Hugues de Saint-Cher († 1263). Bibliste et théologien, éd. L.-J Bataillon o.p., G. Dahan et P.-M. Gy o.p., Turnhout, 2004, p. 341-86. Je rajoute à la version imprimée une deuxième annexe de notes textuelles qui devait paraître sous une forme retravaillée dans un volume de documents sur Hugues de SaintCher. Ce volume est resté à P'état de projet. La pagination originale est notée en marge.

Charles de Miramon, CNRS, CRH (EHESS-CNRS), Paris. miramon@ehess .fr

${ }^{1}$ E. L. Cox, The Eagles of Savoy. The House of Savoy in Thirteenth-Century Europe, Princeton, 1974, p. 144-45.

${ }^{2}$ E. T. Brett, Humbert of Romans. His Life and Views of Thirteenth-Century Society, Toronto, 1984 ; K. Pennington, 'Henricus de Segusio (Hostiensis)' in ID., Popes, Canonists and Texts (1150 - 1550), Variorum, 1993
} 
par son furieux entregent, Henri de Suse vient d'obtenir le diocèse de Sisteron et il profite du concile de Lyon pour poser des questions à des prélats importants dont il insérera les opinions dans la Somme qu'il est en train de rédiger. Trois prélats, trois intellectuels, trois Savoyards aussi qui connaissent bien le jeune Philippe et ses frères. Leur carrière tient sans conteste à leurs mérites mais elle est liée à lascension de lastre savoyard, dont les possessions ont une soudaine importance géopolitique.

Le couvent dominicain de Lyon où nous situons cette conversation a représenté pour chacun d'entre eux un lieu spécial. Hugues s'y fera enterrer, Humbert y finira sa vie. Une tradition, peut-être fausse, avance que la tombe d'Hostiensis s'y trouve aussi ${ }^{3}$. En tout cas, le canoniste dans son testament rédigé juste avant sa mort mentionne spécifiquement le couvent lyonnais et demande à être associé au service liturgique mémorial de son ami Hugues ${ }^{4}$.

Comment nos trois compagnons commentèrent-ils cette brusque nomination qui montrait un pape considérant les institutions de l'Église comme quelque objet qu'il pouvait manipuler à volonté? Certes les procédures avaient été respectées : le vieil Aymeric ayant résigné sa charge s'était retiré à Grandmont. Mais Philippe ne représentait absolument pas un modèle de prélat réformateur. Selon une astuce juridique utilisée par lui et ses frères, il reste archevêque élu et ne se fera pas consacrer. Ainsi, il n'a pas à prendre les ordres majeurs et il se laisse la possibilité de revenir à l'état laïc si le besoin s'en fait sentir, tout en obtenant le pouvoir administratif sur son diocèse. Le pape lui permet, de plus, de conserver son administration de l'évêché de Valence, les bénéfices qu'il perçoit en Angleterre et en Flandres ainsi que la charge de prévôt de Bruges. En 1247, il obtiendra, de surcroît, de garder pendant cinq ans les bénéfices qu'il tenait de l'Église de Lyon avant sa promotion au siège archiépiscopal. Philippe est lun des pions de la famille Savoie, qui construit son pouvoir sur une double base : la création d'un état et le développement d'un réseau bureaucratique constitué de charges ecclésiastiques et curiales dispersées à travers toute l'Europe. Ceci, Innocent IV le comprenait fort bien; lui qui était l'élément le plus brillant d'un autre réseau bureaucratique : les Fieschi ${ }^{5}$.

Quelques mois plus tard, en marge du concile, Hugues avait eu affaire à un prélat bien différent de Philippe de Savoie. Il avait présidé la commission cardinalice statuant sur la canonisation de larchevêque de Cantorbéry, Edmond Rich ${ }^{6}$. Avant sa promotion au siège archi-

${ }^{3}$ Hostiensis étant mort lors du conclave de Viterbe, Kenneth Pennington pense qu'il est improbable qu'il soit enterré si loin de son lieu de décès. Mais, nous sommes à la grande époque où lon bout et dépèce les cadavres pour leur faire accomplir de longs voyages. Sylvie Allemand qui termine une thèse sur les ordres mendiants dans la province franciscaine de Bourgogne ( $\mathrm{xIII}^{\mathrm{e}}-\mathrm{xv}^{\mathrm{e}}$ siècle) nous indique que lauteur de la notice manuscrite du XviII ${ }^{\mathrm{e}}$ siècle sur le couvent dominicain de Lyon conservé aux Archives générales dominicaines (Rome) mentionne la sépulture d'Hostiensis mais indirectement, sans rapporter d'épitaphe ou de description du monument funéraire. Il pourrait s'agir d'une simple tradition locale ou d'une imagination érudite : le testament d'Henri de Suse est publié au xviII ${ }^{\mathrm{e}}$ siècle. Néanmoins, P'église dominicaine lyonnaise a été, au XIII ${ }^{\mathrm{e}}$ siècle, une nécropole de prélats savoyards (Guillaume de Sabine, Otton de Tonengo), cf. A. Paravicini-Bagliani, Cardinali di Curia e 'familiae' cardinalizie (1227-1254), Padoue, 1972, t. 1, p. 91.

${ }^{4}$ A. Paravicini-Bagliani, I testamenti dei cardinali del Duecento, Rome, 1988, p. 139.

${ }^{5}$ Sur limportance de la politique bénéficiale dans la constitution de réseaux bureaucratiques pan-européens, voir J. Sayers, "Centre and Locality : Aspects of Papal Administration in England in the later Thirteenth Century ", dans Authority and Power. Mélanges Walter Ullmann, éd. B. Tierney et P. Linehan,Cambridge, 1980, p. 115-126 (= Law and Records in Medieval England, Variorum, 1988).

${ }^{6}$ Sur le déroulement de ce procès et le rôle d'Hugues de Saint-Cher, voir larticle dans ce volume de Maaike van der Lugt. 
épiscopal, Edmond avait suivi une carrière d'intellectuel : maître ès arts à Oxford, étudiant en théologie à Paris puis, de retour en Angleterre, maître en théologie à Oxford. Il personnifiait pidéal-type du prélat, moine dans le monde. Toute sa vie, il manifesta les marques les plus extravagantes d'ascèse : il ne dormait jamais dans son lit, ne se lavait pas, suivait des jeûnes sévères, était d'une chasteté obsessionnelle, portait continuellement un cilice lui torturant la chair. Cependant les hagiographes ajoutent une autre facette à son portrait : Edmond était un observateur inflexible du droit canonique. À la mort de sa mère, il fut chargé de placer ses deux sœurs au couvent. Il refusa de leur verser une dot, pratique interdite par le droit canonique mais courante dans les faits ${ }^{7}$. Lorsque Edmond se rendit aux facultés, il résigna son bénéfice, alors qu'il aurait pu utiliser son droit à la dispense de résidence accordée aux clercs pour cause d'études ${ }^{8}$. Il s'était gardé de tout pluralisme alors que son entourage, et en particulier son frère Robert, ne le suivit pas dans cette voie 9 . Enfin, devenu archevêque, il tenta de s'opposer à la common law lorsqu'elle lui semblait contraire au droit naturel ou au droit de l'église ${ }^{10}$.

Comme les autres membres de la commission, Hugues a eu entre les mains tant la vita que les miracles du saint. Il est lun des principaux promoteurs de la cause du saint et prononce un discours lors de la liturgie de canonisation. Mais tous les textes issus du procès insistent sur lascèse du saint et sur les nombreux miracles post mortem. Le transitus des sciences lucratives à la théologie et l'héroïque respect du droit de l'église sont passés sous silence. Les pratiques juridiques et administratives d'Edmond n'étaient pourtant pas neutres. Elles s'inscrivent dans le programme des prélats théologiens qui, effrayés par le développement du nouveau droit canonique et du droit royal, pensent que l'Église doit être dirigée par le seul droit divin, c'està-dire la théologie. C'est la position d'un autre membre de la commission de canonisation : Robert Grosseteste, évêque de Lincoln, suffragant et ami d'Edmond Rich. Robert crut, du reste, trouver auprès du cardinal dominicain un appui pour sa croisade réformatrice. En 1245, il écrit une lettre à Hugues de Saint-Cher pour lui demander d'envoyer des mendiants aider larchevêque de Cantorbéry car eux seuls connaissent les iura Dei et pas seulement les iura regni vel civilia et canonica ${ }^{11}$. La requête du bouillant évêque de Lincoln ne semble pas avoir été suivie d'effets.

Que pensait en 1245, Hugues des pratiques bénéficiales d'Edmond? On sait que moins de dix ans auparavant, il avait supervisé une dispute solennelle à l'Université de Paris contre la pluralité des bénéfices. Sa position avait-elle évolué depuis son accession au cardinalat, était-il devenu une figure du compromis ou de la compromission? Le but n'est pas ici de désigner les traitres et les purs et de distribuer rétrospectivement les bons et les mauvais points, ni de faire une chronique désabusée de la décadence de linstitution ecclésiastique au bas Moyen

\footnotetext{
${ }^{7}$ Vita de Pontigny, c. 7 (éd. E. Martène et U. Durand, Thesaurus novus anecdotorum, Paris, 1717, t. 3, col. 17791780); J. H. Lynch, Simoniacal Entry into Religious Life from 1000 to 1260. A social, economic and legal study, Columbus, 1976.

${ }^{8}$ Edmond finit néanmoins par modérer sa conception de la résidence et accepte la charge de trésorier du chapitre de Salisbury. En six mois, il réussit à dépenser en aumônes le revenu de lannée. Labbé Étienne de Laxton tente de lui enseigner le b.a.-ba de la gestion : ne pas dépenser plus que ce que Pon gagne. Edmond répond qu'il agit ainsi car les langues de serpent traitent les théologiens d'avares (Vita de Pontigny, ed. cit., col. 1795).

${ }^{9}$ C. H. Lawrence, St. Edmund of Abingdon. A Study in Hagiography and History, Oxford, 1960, p. 144-145.

${ }^{10}$ Vita de Pontigny, op. cit., col. 1806-07.

${ }^{11}$ Robert Grosseteste, Epistola, n 115 (éd. Luard, Londres, 1861 [Rolls Series 25] p. 326).
} 
Âge mais de comprendre les ressorts d'un des principaux débats qui agitèrent l'Église du XIII ${ }^{\mathrm{e}}$ siècle.

Les historiens se rangent d'ordinaire dans deux camps opposés lorsqu'ils jugent de linstitution bénéficiale au Moyen Âge. La vision la plus courante reprend les analyses des réformateurs médiévaux. Elle explique qu'office et bénéfice étaient dans un premier âge strictement liés. Puis, dans un deuxième temps, des abus déréglèrent le système. Certains clercs poussés par lavarice en vinrent à multiplier sans raison les bénéfices ${ }^{12}$. Prenant le contre-pied de ce constat de déliquescence, d'autres historiens avancent que les transformations du système bénéficial au XIII ${ }^{\mathrm{e}}$ siècle furent utilisées par les nouvelles administrations centrales (curie pontificale, cours royales) pour rémunérer leurs serviteurs ${ }^{13}$. Les perversions de Pinstitution furent ainsi bénéfiques au développement de l'État.

On peut renvoyer les deux explications dos à dos. Les concepts techniques d'office et de bénéfice sont forgés par le droit canonique à la fin du XII ${ }^{\mathrm{e}}$ siècle et durant le XIII ${ }^{\mathrm{e}}$ siècle dans une chronologie concomitante à celle de l'émergence du pluralisme. Il n'y a pas 'd'âge d'or' du bénéfice. L'enfant est né déjà perclus de ses vices. De même, si les pouvoirs centraux et particulièrement les papes acquièrent des pouvoirs nouveaux de dispense et de provision, ils n'en usent pas de manière rationnelle pour huiler la machine bureaucratique. Ce sont les individus qui pétitionnent ladministration et non pas ladministration qui organise la gestion des ressources. La curie et les cours royales n'ont aucune mémoire des faveurs déjà distribuées ; elles distribuent provisions et dispenses aux audacieux et astucieux, à ceux qui peuvent jouer du népotisme, de lappui d'un réseau, de la faveur des grands et d'une bonne connaissance des nouveaux mécanismes juridiques ${ }^{14}$.

Cet article ne s'intéressera pas aux aspects sociologiques du pluralisme, ni au droit bénéficial dans son détail. Nous étudierons la question du pluralisme à partir d'un angle différent : celui de lopinion publique. En effet, la question du pluralisme a émergé brutalement comme un problème de société, à P'Université de Paris puis parmi les clercs lettrés français et anglais. Dans ce petit monde où linformation circule vite, chacun a dû choisir son camp. La polarisation du débat est ainsi révélatrice des différentes tensions qui traversent la société ecclésiastique de l'époque : tension devant les transformations sociales et économiques de l'église séculière ; tension devant la montée d'un groupe de clerc d'un nouveau type, les diplômés de l'Université; tension entre les disciplines; tension autour des modèles d'organisation ecclésiale; tension entre les rêves ecclésiologiques du retour à une église apostolique pure et simple et la réalité de la bureaucratisation du pouvoir politique et ecclésiastique. Acteur majeur du débat, Hugues de Saint-Cher par ses choix doctrinaux, voir par ses contradictions sera analysé comme lune des figures représentatives de sa génération.

Nous suivrons la chronologie des débats sur le pluralisme sur un laps de temps limité qui court des années 1230 à 1238. Hugues de Saint-Cher n'intervient dans le débat qu'en 1236-

\footnotetext{
${ }^{12}$ Ainsi G. Le Bras, Institutions ecclésiastiques de la Chrétienté médiévale, t. 2, 1964, p. 571-576.

${ }^{13}$ G. Barraclough, Papal Provisions : Aspects of Church History, Constitutional, Legal and Administrative in the Later Middle Ages, Oxford, 1935.

${ }^{14}$ Nous reprenons les conclusions de P. Montaubin, Le gouvernement de la grâce. La politique bénéficiale des papes au XIII $^{e}$ siècle dans la moitié nord du Royaume de France, Thèse, Paris I, 1998. Sur les provisions pontificales au xIII ${ }^{e}$ siècle voir aussi M. BÉGOU-Davia, L'interventionnisme bénéficial de la papauté au xIII ${ }^{e}$ siècle. Les aspects juridiques, Paris, 1997.
} 
38 mais pour comprendre sa position et les raisons de son intervention, il faut se déplacer quelque peu en amont lorsque le problème émerge à l'Université. La date de fin de la fourchette chronologique retenue correspond à un silence de la documentation. Nous ne connaissons pas de source qui permette de suivre les positions d'Hugues après ces années. C'est dommage car les questions disputées par le maître dominicain en 1236-38 ne constituent ni un tournant, ni un sommet du débat, mais un simple épisode. Les combats se poursuivent durant tout le XIII ${ }^{\mathrm{e}}$ siècle. Mais, avant de dévider le fil de la chronologie, il faut présenter le cadre général de la norme en matière de pluralisme.

\section{LA PLURALITÉ DES BÉNÉFICES : UNE NOUVEAUTÉ AU XIII ${ }^{\mathrm{E}}$ SIÈCLE}

Les théologiens scolastiques prétendent bâtir une théorie bénéficiale en tirant des règles éternelles des Saintes Écritures. En cela, ils témoignent d'une relative naïveté car le concept de bénéfice est bien proprement juridique et médiéval. Du reste, quand les théologiens vont traiter de la question dans les années 1230, ils utiliseront les réflexions des décrétistes du XII ${ }^{\mathrm{e}}$

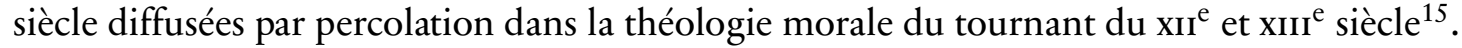
Dans le droit traditionnel qui prévaut jusqu'au milieu du XII ${ }^{\mathrm{e}}$ siècle, il existe depuis longtemps des canons qui interdisent à un prêtre de tenir plusieurs églises et qui comparent ce clerc coupable à un monstre à plusieurs têtes ou à un mari adultère. La réalité sociale que lon devine derrière ces règles c'est celle d'un curé qui tiendrait plusieurs églises proches (par exemple dans la même localité). À ces canons, d'autres sont ajoutés à partir des années 1170. Alexandre III mène alors une politique vigoureuse contre le cumul des revenus. Mais, lobjet est abordé par un biais particulier qui sont les règles de mutation. Le pape légifere à ce sujet lors du concile de Latran III $(1179)^{16}$. La règle ne fonctionnant pas bien, elle sera modifiée lors de Latran IV (1215) par Innocent III dans le canon De multa. Ce canon De multa marque une nouvelle inflexion. Innocent III s'y réserve le droit de dispenser des règles de linterdiction de cumul pour les gens 'importants et lettrés'. Un nouveau venu apparaît sur la scène bénéficiale : la dispense.

Ces jalons normatifs, rapidement évoqués, seront utilisés dans les débats dans lesquels Hugues de Saint-Cher s'illustrera. Néanmoins, on aurait tort de les analyser stricto sensu comme traitant de la pluralité des bénéfices. D'un simple point de vue sémantique aucun n'utilise le terme de pluralitas et le mot beneficium est peu fréquent et possède longtemps la signification large de 'revenu'. Il faut attendre le développement du nouveau droit administratif de l'Église à partir des années 1170 pour que le concept de bénéfice ecclésiastique se cristallise lentement.

Ces progrès de la science canonique sont malgré tout moins importants que deux évolutions de léglise médiévale qui vont alimenter le terreau sur lequel le pluralisme va fleurir. Le cumul traditionnel s'organisait sur une base locale alors que les nouveaux pluralistes empilent

\footnotetext{
${ }^{15}$ La question du pluralisme bénéficial en droit canonique a été bien traitée par K. Pennington, « The Canonists and Pluralism in the Thirteenth Century ", Speculum, 51 (1976), p. 35-48 et ID., Pope and Bishops. The Papal Monarchy in the Twelfth and Thirteenth Centuries, Philadelphie, 1984, p. 115-153.

${ }^{16} \mathrm{M}$. BÉGou-Davia, «De Pangélisme au réalisme : la prohibition du cumul bénéficial à la fin du xiI ${ }^{\mathrm{e}}$ siècle et au début du xiII ' siècle ", dans Nonagesimo anno. Mélanges en hommage à Jean Gaudemet, éd. C. Bontems,Paris, 1999 , p. $158-86$.
} 
des bénéfices à travers toute l'Europe. Pour que cela soit réalisable dans la pratique, il faut qu'une société ait atteint un niveau suffisant de monétarisation et d'utilisation de l'écrit pour permettre une gestion à distance de revenus. D'autre part, auparavant les clercs ambitieux pouvaient espérer jouir des revenus de quelques églises paroissiales ou chapellenies. Dorénavant, un chasseur de bénéfices est à la recherche de prébendes canoniales. Les chapitres cathédraux à partir du XIII ${ }^{\mathrm{e}}$ siècle se sont repliés sur leurs activités cérémonielles et ont réduit leurs fonctions sociales. Pour une partie de lopinion cléricale, leurs ressources pouvaient former la base d'un système d'emplois fictifs. Il serait très difficile, faute de sources adéquates, de tracer la carte européenne du pluralisme mais il est vraisemblable qu'elle révélerait un semis de chapitres cossus situés dans les régions les plus avancées tant dans la monétarisation que dans lutilisation de l'écrit et des nouvelles règles du droit.

Cette approche statistique n'est évidemment pas celle d'un acteur médiéval. Un clerc analysait le pluralisme à partir de son expérience personnelle : les bonheurs et les malheurs de sa carrière ecclésiastique. Il est, d'autre part, influencé par lopinion publique. La notion d'opinion publique peut paraître anachronique pour le Moyen Âge mais nous l'entendons ici dans un sens restreint. L'Université peut être analysée comme un espace public clérical tant sur le plan politique - il s'agit d'un lieu d'échanges et de discussions soustrait au pouvoir et souvent critique vis-à-vis de celui-ci - que sur le plan sociologique — la communauté des maîtres et des étudiants se distingue du monde des prélats entourés de leur familia et de la masse des laïcs ${ }^{17}$.

L'intervention d'Hugues sur le pluralisme n'est pas, comme nous le verrons, un acte isolé. Au contraire, il s'agit d'une prise de position contre d'autres maîtres parisiens dans une atmosphère conflictuelle. Il faut essayer de restituer les termes de ce débat en se plaçant dans la situation à l'époque d'Hugues à lintersection de trois réseaux : la communauté des maîtres en théologie de P'Université de Paris, Pordre naissant des dominicains et plus accessoirement les prélats d'origine savoyarde. On ne peut faire aussi l'économie de suivre les méandres de la politique ecclésiastique dans les années où Hugues élabore sa doctrine. La pluralité des bénéfices n'est pas matière à pure spéculation. Les positions de chacun s'inscrivent sur un échiquier sur lequel doivent se replacer les évolutions de la politique pontificale, les luttes de pouvoir à l'intérieur de l'Université, les derniers textes conciliaires et les grandes affaires judiciaires du moment.

Le pluralisme entre sur la scène du théâtre des débats universitaires parisiens dans les années où Hugues débute sa régence. Le paradoxe est qu'il s'agit précisément des années au cours desquelles les théologiens universitaires se détournent massivement des aspects moraux et pratiques qui constituaient une part si importante des ouvres de Pierre le Chantre et de ses continuateurs : Robert de Courson puis Guy d'Orchelles. Dans les années 1230, les travaux de l'école théologico-morale parisienne ne sont pas mis à jour. Ils ne sont pourtant pas encore obsolètes. Ils restent les premiers ouvrages de référence vers lesquels Hugues et ses

\footnotetext{
${ }^{17}$ Nous faisons allusion ici aux thèses classiques de J. Habermas, L'espace public. Archéologie de la publicité comme dimension constitutive de la société bourgeoise, Paris, $1992^{2}$ (orig. allemand 1962). L'Université de Paris ne s'est pas voulue uniquement un espace de débat mais aussi une instance normative cf. E. Marmursztejn, Un 'troisième pouvoir'? Pouvoir intellectuel et construction des normes à l'Université de Paris à la fin du xiII siècle d'après les sources quodlibétiques (Thomas d'Aquin, Gérard d'Abbeville, Henri de Gand, Godefroid de Fontaines), Thèse, ÉHÉSS, 1999 [= E. MarmurszTejn, L'autorité des maîtres. Scolastique, normes et société au xiII siècle, Paris, 2007].
} 
contemporains peuvent se tourner pour trouver des solutions à un problème comme celui du pluralisme. Un rapide détour à travers les ouvres de Pierre le Chantre et Robert de Courson est ainsi nécessaire pour découvrir le socle à partir duquel la réflexion d'Hugues et de ses confrères s'élabore.

\section{LE CUMUL DES REVENUS ECCLÉSIASTIQUES DANS LA THÉOLOGIE MORALE PARISIENNE}

Dans son Verbum Abbreviatum, une critique systématique de toutes les formes de superfluité dans PÉglise, Pierre le Chantre († 1197) consacre un chapitre à attaquer les clercs qui cumulent des dignités dans plusieurs églises; il les compare à des monstres ${ }^{18}$. Dans sa Somme des sacrements, il aborde la question sous un angle plus technique et concret $^{19}$ Sa casuistique est abondante mais elle ne porte pas sur la pluralité mais sur les modalités de la collation et de la commutation qui sont perçus comme de possibles actes simoniaques. Nulle part, il n'aborde la question du pluralisme. Il y avait là sans doute des raisons personnelles. Son élève, Robert de Courson nous apprend en effet que Pierre le Chantre cumulait deux prébendes : chanoine à Reims et chantre à Paris. Pour essayer de défendre l'honneur de son maitre, Robert de Courson va ainsi consacrer un chapitre de sa Somme à répondre à la question "Est-il licite de posséder plusieurs églises ou prébendes? " La question sur le pluralisme occupe le chapitre 17 de sa Somme, loin du chapitre 8 où il traite de la simonie ${ }^{20}$. La question bénéficiale acquiert dans son œuvre une autonomie qui s'explique par la disjonction en droit canonique depuis les années 1180 entre bénéfice et simonie. En effet, le plan systématique qu'adopte Bernard de Pavie pour sa collection de décrétales, la Compilatio Prima, place les bénéfices dans le troisième livre consacré au clergé et la simonie dans le cinquième livre traitant du crime ${ }^{21}$. Le plan de la Compilatio Prima sera repris sans grandes modifications dans les compilations ultérieures et en particulier dans le Liber Extra.

Robert de Courson, prélat austère et traditionaliste, est évidemment contre le pluralisme. Il ne laccepte que dans trois cas. Si les bénéfices dans une région sont trop minces, il peut être indispensable d'en cumuler plusieurs pour atteindre un revenu suffisant. Lorsqu'il y a une pénurie de clercs, comme c'était cas dans l'Église primitive, il peut être légitime de tenir en surcroît de son bénéfice principal (intitulatum) un deuxième en garde (commendatum); les fruits de ce bénéfice accessoire seront réservés aux pauvres et on se défera de celui-ci dès que Pon pourra trouver un candidat valable ${ }^{22}$. Enfin, il peut exister des rares cas de dispense pour des clercs exceptionnels. C'est le cas de Pierre le Chantre qui selon Robert était une véritable

\footnotetext{
${ }^{18}$ PL 205, col. 112-118. Pour un traitement plus complet de la position de Pierre le Chantre, cf. J. BaLdwin, Masters, Princes and Merchants. The Social Views of Peter the Chanter and his Circle, Princeton, 1970, p. 117-121.

${ }^{19}$ La casuistique de Pierre le Chantre est parfaitement synthétisée dans la table des matières de l'édition de sa Summa de Sacramentis et Animae Consiliis par J.-A. Dugauluier, t. III 2 b, s. v. 'Bénéfices ecclésiastiques'.

${ }^{20} \mathrm{La}$ Somme de Robert est inédite, nous utilisons le ms. PARIS, BnF, lat. 14524, f. 73r-74v.

${ }^{21}$ Les cinq compilations qui précèdent le Liber Extra sont éditées par E. FriedBERG, Quinque compilationes antique, Leipzig, 1886 (réimp. anast. Graz, 1956). Pour alléger les notes, les allégations juridiques suivront les usages cf. S. Kuttner, " Notes for contributors ", Bulletin of Medieval Canon Law, 5 (1975), p. 179-181. L'édition classique du Décret de Gratien et du Liber Extra est E. Friedberg éd., Corpus Iuris Canonici, Leipzig, 1879 [= réimpr. anast. Graz, 1959].

${ }^{22} \mathrm{La}$ distinction entre bénéfice intitulatum et bénéfice commendatum est classique à lépoque où Robert lemploie ; elle se trouve déjà chez Gratien cf. C. 21 q. 1 d. p. c. 6.
} 
« colonne de l'église de Reims »; son départ à Paris menaçait de faire s'écrouler l'édifice. Mais peu de monde a cette prééminence. Robert se gausse de la prétention des enseignants parisiens qui revendiquent le droit d'être pluraliste car leur magistère est universel alors que leur état n'est pas plus saint que celui d'un moine de Clairvaux. Un péché, véniel pour d'autres, est mortel pour eux ${ }^{23}$. Du reste, selon lui, les maîtres pluralistes ont tous résigné leurs bénéfices supplémentaires avant de mourir, preuve qu'ils se sentaient en état de péché.

La position de Robert est très proche de celle des canonistes bolonais contemporains. Tancrède dans son commentaire sur la Compilatio Secunda dresse une typologie semblable des cas où le pluralisme est autorisé : pauvreté des églises, rareté des clercs, dispense. Cependant, le juriste accorde plus d'importance à la dispense qui peut provenir non seulement du pape mais aussi des évêques ${ }^{24}$. Les choix de Robert sont donc modérés. A ses yeux, le pluralisme reste encore un phénomène minoritaire : celui de chanoines qui combineraient dans une même région deux prébendes. Il donne lexemple de quelqu'un qui aurait sa stalle en même temps à Chartres et à Paris pour montrer les inconvénients de cette situation si le pluraliste est convoqué dans les deux chapitres le même jour ou s'il doit choisir son camp en cas de litige entre les deux églises. Il n'y a pas vraiment de conscience chez Robert du système pluraliste européen qui est en train de se mettre en place. Le maître laisse malgré tout transparaître une certaine inquiétude. Parmi les arguments en faveur du pluralisme, le plus dérangeant était celui qui consistait à dire que le pape était parfaitement au courant de la situation et qu'il lencourageait par ses dispenses ou ne disait rien, et selon ladage «qui dit mot consent ${ }^{25}$. » Robert répond, quelque peu gêné, que le pape n'a certainement pas accordé ces dispenses en connaissance de cause et qu'il a dû se faire circonvenir par des fausses informations ${ }^{26}$.

La riche question de Robert de Courson sur le cumul d'églises et de prébendes n'a trouvé aucun écho dans lopinion parisienne du tournant du XII ${ }^{\mathrm{e}}$ et $\mathrm{xIII}^{\mathrm{e}}$ siècle. La pastorale est muette à ce sujet ${ }^{27}$. Les Sommes morales n'en parlent pas $^{28}$. Il s'agit pourtant d'une époque de fermentation normative.

\footnotetext{
${ }^{23}$ "Sed quidam obiciunt sic. Nos docendo servimus omni ecclesie et dignus est operarius mercede sua; ergo in omni ecclesia debemus prebendari sed tales obiectiones cum summa irrisione explodende sunt et exsufflande quia qui legit publice sacram scripturam iter maioris perfectionis $<$ non $>$ arripuit quam aliquis Clarevalensis »,ms. lat. 14524 , f.74r.

${ }^{24}$ Tancrède, ad $2^{\text {a }}$ Comp. 3.4.1 [=X 3.5.15] (éd. K. Pennington, « The Canonists and Pluralism », p. 38, n. 16). Le juriste est néanmoins plus souple que Robert en imaginant que, dans certains cas, un bénéfice pourrait être concédé à un laïc (Ibid., p. 37, n 15).

${ }^{25}$ Les quidam qui soutiennent largument du pluralisme comme coutume reprennent Huguccio, Summa, ad C. 21 q. 1 d. a. c. 1, vis 'in duabus' (éd. K. Pennington, Popes and Bishops ..., p. 137, n. 76).

${ }^{26}$ À la même époque, à Bologne, Tancrède ad $1^{\mathrm{a}}$ Comp. 3.5.6 [= X 3.5.5] (éd. K. Pennington, "The Canonists and Pluralism... ", p. 37, n. 15) répondait au même argument en expliquant que le pape avait expressément refusé le pluralisme et les cas acceptés devaient être compris comme des dispenses.

${ }^{27}$ Sur le portrait du mauvais prélat dans les sermons parisiens cf. N. BÉRIou, L'avènement des maîtres de la Parole. La prédication à Paris au $\mathrm{xIII}^{e}$ siècle, Paris, 1998, t. 1, p. 321 et J. LONGÈre, Euvres oratoires des maîtres parisiens au $\mathrm{xII}^{e}$ siècle, Paris, 1975, t. 1, p. 371-98.

${ }^{28}$ Dans la ligne de Pierre le Chantre, la question des prébendes est abordée au sein de la discussion sur la simonie dans la Somme de maître Martin qui date des dernières années du xiI e siècle, cf. R. Heinzmann, Die Compilatio questionum theologiae secundum Magistrum Martinum, Munich, 1964, p. 37. Étienne Langton effleure le même sujet dans sa question De simonia (ms. Paris, BnF, lat 14556, f. 211ra-211va). Voir aussi Gui D'Orchelles, Tractatus de Sacramentis, $\mathbb{\$}$ 201-205 (éd. D. et O. VAn DEN Eynde, St. Bonaventure N. Y., 1953).
} 


\section{LA CONSTRUCTION D'UNE OPINION PUBLIQUE SUR LA QUESTION DES BÉNÉFICES AU XIII ${ }^{\mathrm{E}}$ SIÈCLE}

Lors de sa légation en France entre 1213 et 1215, Robert de Courson rédige ainsi plusieurs canons conciliaires contre le pluralisme. Le dix-neuvième canon du concile de Paris interdit le cumul de personnat, défini ici comme un bénéfice avec charge d'âmes ${ }^{29}$. Le texte est novateur car il marque lapparition d'une nouvelle typologie (bénéfice avec ou sans charges d'âmes, personnat, dignitaires) qui se superpose aux anciennes classifications fondées sur les fonctions (abbé, évêque, doyen, chantre, etc. ${ }^{30}$. Peu de temps après, le canon De Multa de Latran IV s'inspirera des formulations des conciles de la légation de Robert de Courson mais ajoutera une grande nouveauté : la possibilité d'une dispense spéciale pour les intellectuels.

Le canon De multa va être rapidement commenté dans les écoles de Bologne. Il sera très mal reçu par les deux principaux canonistes du moment : Jean le Teutonique et Tancrède. Les deux juristes vont s'efforcer de prouver contre la lettre du texte que la dispense en cas de pluralisme n'est pas de la seule réserve pontificale mais qu'elle appartient aussi au pouvoir de l'évêque ${ }^{31}$. Cela montre bien la réticence des intellectuels devant linterventionnisme du Saint-Siège dans la politique bénéficiale. Les professeurs bolonais vont s'opposer au canon de Latran IV non seulement par leurs gloses mais aussi plus subtilement dans leur pouvoir de tri des normes pontificales. En 1226, Tancrède se rend à Rome pour travailler sur le registre d'Honorius III. Il va noter par une croix dans la marge du manuscrit les lettres papales qu'il va extraire pour les organiser dans sa Compilatio quinta. Il omet sciemment la décrétale Expectavimus de novembre 1219 : une lettre extrêmement dure envoyée aux prélats espagnols par laquelle Honorius III réaffirmait le pouvoir exclusif du pape en matière de dispense de pluralisme ${ }^{32}$. Du reste certains scribes rajouteront cette décrétale comme extravagante à la Compilatio Quinta ${ }^{33}$. L'interprétation rigide du canon De multa par Honorius III semble gêner même les collaborateurs les plus proches du pontife. Pandulphe, légat en Angleterre et au Pays de Galles entre 1218 et 1221, envoie ainsi une lettre à la curie pour demander si les clercs peuvent cumuler un bénéfice avec charge d'âme et un archidiaconat sans demander une dispense pontificale. Honorius lui répond sur un ton agacé que c'est évidemment impossible ${ }^{34}$.

\footnotetext{
${ }^{29}$ Concile Paris 1213, c. 19 (MAnsI, t. 22, col. 824) ; Rouen 1214, c. 21-22 (Ibid., col. 903); Montpellier, 1214, c. 25 (Ibid., col. 945) a une formulation moins technique.

${ }^{30}$ Nous ne connaissons aucune étude de la genèse de cette nouvelle typologie. Dans sa forme aboutie : un office est dit simple lorsqu'il n'y est annexé qu'un pouvoir d'administration ; il est un personnat lorsqu'il y est annexé de plus un droit de préséance; il devient une dignité lorsqu'à loffice est annexé un droit de préséance et un pouvoir de juridiction. Il faut faire attention au fait que le mot personnat change de sens au XIII ${ }^{\mathrm{e}}$ siècle dans le vocabulaire administratif. Pour son sens antérieur, voir infra.

${ }^{31}$ Dans les sources que nous avons consultées, Jean le Teutonique est le premier à employer le terme de pluralitas.

${ }^{32}$ P. Pressutti, Regesta Honorii Papae III, Rome, 1888-1895, nº 2268 (Mansi, t. 22, col. 1098-1100). Sur les circonstances de cette lettre, voir P. Linehan, The Spanish Church and the Papacy in the Thirteenth Century, Cambridge, 1971, chap. 1.

${ }^{33}$ L. Boyle, "The Compilatio quinta and the Registers of Honorius III », Bulletin of Medieval Canon Law, 8 (1978), p. 9-19; K. Pennington, "The French Recension of Compilatio tertia ", Bulletin of Medieval Canon Law, 5 (1975), p. 53-71 ici p. 68-69 (repris dans K. Pennington, Popes, Canonists and Texts 1150-1550, Variorum, 1993). Cette décrétale est citée comme extravagante dans la première version (1222-1226) de la Summa de Casibus de Raymond de Peñafort.

${ }^{34} 5^{\mathrm{a}}$ Comp. 3.4.2 ; cf. J. SAYERs, Papal government and England during the pontificate of Honorius III, Cambridge,
} 
Dans ces années, Popinion publique tant bolonaise que curiale cherchait à obtenir du pape une jurisprudence assouplissant le canon De multa.

Le débat bolonais ne semble pas avoir été reçu à Paris dans les années 1220. Lactivité littéraire de Pécole canonique parisienne est nulle à cette époque et Paris semble être devenu pour cette matière un centre d'enseignement tout à fait mineur. La culture normative des maîtres parisiens en théologie des années 1220 en matière de pluralisme paraît peu informée des nouveautés doctrinales cisalpines. C'est ce que révèlent les actes de la légation de Jean Halgrin dans la péninsule ibérique en 1228-29. Jean Halgrin est maître régent en théologie avant 1217. Il a laissé une œuvre homilétique et exégétique encore très largement méconnue ${ }^{35}$. Il semble néanmoins représenter à Paris un courant conservateur fidèle à la théologie moraloexégétique de Pierre le Chantre et d'Étienne Langton et hostile au nouvel Aristote. Hugues de Saint-Cher a peut-être suivi son enseignement. En tout cas, limportance que Jean Halgrin accorde à la prédication et à la réforme de l'Église lui donne des accents pré-mendiants. Du reste, son élève Robert Bacon, ami et condisciple d'Edmond Rich, devenu prieur du couvent dominicain d'Oxford décalquera un commentaire de son maître dans son propre ouvrage ${ }^{36}$. Dans les années 1225, Jean Halgrin va progresser rapidement dans la carrière ecclésiastique. En 1227, il est créé cardinal par le nouveau pape Grégoire IX et envoyé en légation en Espagne et au Portugal ${ }^{37}$. La réforme des chapitres cathédraux est lune des idées fixes de Jean. Lors de conciles provinciaux, il promulgue des versions du canon De multa de Latran IV mais pour le légat la référence juridique fondamentale reste le premier canon du concile de Tours de 1163, présidé par Alexandre III, qui interdisait la division des prébendes ${ }^{38}$. Cet alliage du canon de Latran IV et de celui du concile de Tours est tout à fait révélateur de lapproche du problème par le clergé français réformateur qui interprète le canon De multa comme une condamnation du personnat.

Le personnat est une institution paroissiale relativement méconnue mais qui a eu une grande importance tant en France qu'en Angleterre du xi ${ }^{\mathrm{e}}$ au XIII ${ }^{\mathrm{e}}$ siècle $^{39}$. Elle s'inscrit dans Phistoire complexe du partage des pouvoirs et des revenus d'une paroisse rurale entre le patron laïc, l'évêque et le desservant. Le personnat insère dans le système un quatrième individu (la persona). Il s'agit d'un clerc, généralement un chanoine bien introduit localement, qui est présenté par le patron et confirmé par l'évêque et qui nomme un vicaire pour desservir la paroisse. Le titulaire du personnat touche une partie des revenus de léglise; en contrepartie, il verse le synodicum à lévêque et un important droit de relief lors de sa confirmation.

À l'origine, il s'agit sans nul doute d'un artifice pour conserver la majeure partie des revenus d'une église entre les membres laïcs et clercs de la famille du fondateur, d'autant plus que les

1984, p. 154-56.

${ }^{35}$ La seule étude sur l'œuvre de Jean Halgrin (ou Jean d'Abbeville) est la notice de J. Ribaillen dans le Dictionnaire de Spiritualité.

${ }^{36}$ B. Smalley, «Robert Bacon and the Early Dominican School at Oxford ", Transactions of the Royal Society, 30 (1948), p. 1-19.

${ }^{37}$ Sur la légation de Jean : P. Linehan, The Spanish Church and the Papacy in the Thirteenth Century, chap. 2.

${ }^{38}$ Linehan, op. cit., p. 32. Pour les canons réformateurs de Jean Halgrin, voir le Concilium incerti loci, cc. 1, 2, 13 (Mansi, t. 22, col. 1089-1092) renvoyant au Concile de Tours 1163, c. 1 (Mansi, t. 21, col. 1176) = $1^{\text {a }}$ Comp. 1.5.10.

${ }^{39}$ Sur le personnat voir B. Delmaire, Le diocèse d'Arras de 1093 au milieu du xiv é siècle, Arras, 1994, t. 1, p. 109-119 qui renvoie à la bibliographie antérieure. Personnat a donné langlais parson («curé »). 
personnats peuvent se cumuler. Les personnats sont interdits dès le concile de Clermont de 1092 mais les textes conciliaires restent flous et les pratiques perdurent longtemps. Le personnat régresse dans le Nord de la France durant le xII ${ }^{\mathrm{e}}$ siècle et il devait apparaître pour Jean Halgrin, originaire d'Abbeville, comme une mauvaise coutume heureusement abolie. Dans POuest de la France et en Angleterre, linstitution sera beaucoup plus longue à éradiquer. Malgré de nombreuses lettres papales et différents conciles provinciaux, les personnats survivent au milieu du XIII ${ }^{\mathrm{e}}$ siècle comme le montre le pouillé du diocèse de Rouen des années $1240^{40}$.

On pourrait penser que personnat et pluralité des bénéfices sont les deux faces d'une même monnaie. On n'aurait pas totalement tort. D'un point de vue fonctionnel, les deux institutions se chevauchent et dans lesprit des prélats français peu au fait de la science canonique, il y a certainement confusion. Néanmoins, sous langle normatif tout les sépare. D’un côté une pratique régionale centrée sur l'église paroissiale, enracinée dans le tissu local et apparaissant de manière fugitive dans l'édifice du droit, de lautre une technique fondée sur une réflexion abstraite et juridique autour de loffice ecclésiastique et des chapitres cathédraux, au service d'une élite cléricale internationale. Le personnat se fondait dans le régime de la coutume ecclésiastique et dans la théorie que chaque église pouvait avoir des traditions propres qui n'avaient pas à être sanctionnées par la papauté. La pluralité s'appuie sur le mécanisme de la dispense qui devient au cours du XIII ${ }^{\mathrm{e}}$ siècle de plus en plus fondamental dans linstitution ecclésiastique.

Jusqu'à la fin des années 1220 , le pluralisme bénéficial n'a pas d'existence dans lopinion parisienne. Certes, tout le monde connaît des cas de cumul de revenus, par exemple le rassemblement entre de mêmes mains de plusieurs personnats. Mais ceci était perçu comme la perversion locale d'une pureté originelle ; une mauvaise coutume qu'il fallait éradiquer. Ceux qui avaient lu ou avaient eu vent du canon De multa le percevaient comme une arme dans cette lutte et non pas comme un texte qui établissait un nouveau monopole pontifical en matière de dispense. Le retard parisien s'explique ainsi de deux raisons. D'une part, labsence d'une réflexion doctrinale canonique conduit les maîtres parisiens à être moins attentifs aux nouvelles normes promulguées par Rome. D’autre part, certains particularismes institutionnels, comme le personnat, forment un prisme qui brouille les catégories d'interprétation. Le chemin que vont parcourir dans les années suivantes les maîtres parisiens - et en premier lieu Hugues de Saint-Cher - va faire évoluer rapidement l’opinion cléricale. La pluralité des bénéfices va tout d'abord devenir un objet de polémique et acquérir de ce fait des contours plus précis et des enjeux nouveaux. L'ardeur du débat va ensuite pousser les participants à rechercher de nouveaux arguments.

Pour la communauté des maîtres de PUniversité de Paris, on peut percevoir finement la chronologie de ce renouvellement d'horizons. Entre février 1229 et avril 1231, Paris est secoué par une dure grève universitaire. Le conflit concerne en premier lieu la liberté de l'Université, c'est-à-dire son indépendance judiciaire vis-à-vis du pouvoir épiscopal — l'évêque de Paris est à l'époque Guillaume d'Auvergne - et du pouvoir royal. La grève arrivera à son terme lorsque

\footnotetext{
${ }^{40}$ Pouillé édité dans Recueil des Hist. de France, t. 23, p. 225-329 qui montre que larchevêque franciscain, ancien maître régent à Paris, Eudes Rigaud n'a pas hésité à nommer de nouveaux personnats, voir par exemple le cas de Manneville-sur-Risle (Ibid., p. 237).
} 
sort de la chancellerie pontificale la bulle Parens Scientiarum ${ }^{41}$.

En 1230-31, les maîtres régents en théologie étaient divisés entre ceux qui se sentaient solidaires des maîtres ès arts et des étudiants qui formaient le fer de lance du conflit et ceux qui rejetaient cette association. Certains avaient fermé leur école, d'autres lavaient conservée ouverte ou adoptaient une position neutre. Il ne faudrait pas réduire ces lignes de fracture au simple bras de fer institutionnel autour des libertés universitaires. La redoutable efficacité des grèves ecclésiastiques au Moyen Âge tient au fait qu'elles sont, comme les interdits, perçues par tous comme de véritables tragédies, et le désarroi psychologique peut faire fermenter les esprits $^{42}$. C'est ainsi au cours de la grève que le maître séculier Jean de Saint-Gilles se convertit de manière spectaculaire et entre dans lordre dominicain avec sa chaire; plantant le germe de la polémique autour de la deuxième chaire des prêcheurs. Nous conservons, malheureusement, peu de documents qui permettent de comprendre le jeu politique et les positions des différents maîtres. Le manuscrit Nouvelles acquisitions latines 338 de la Bibliothèque nationale de France est ainsi une source précieuse. Il s'agit d'une collection de sermons prêchés à Paris de septembre 1230 à août 1231 soit par des membres des ordres mendiants, soit par des maîtres, soit, en minorité, par des dignitaires de la cathédrale. Le manuscrit est connu des historiens ${ }^{43}$. Cependant, son contenu n'a pas été assez mis en relation avec le déroulement du conflit universitaire alors que les sermons peuvent être le lieu où s'expriment des positions politiques et où lon règle des comptes entre adversaires ${ }^{44}$.

On pourrait analyser le Nouvelles acquisitions 338 comme une collection hétéroclite de sermons collectés par un reportateur. Il nous semble pourtant que lensemble reflète un système cohérent de répartition des sermons entre les différents maîtres et les prêcheurs mendiants et que nous nous trouvons en face d'un miroir fidèle de la prédication universitaire officielle durant ces deux années ${ }^{45}$. C'est évidemment, les maîtres opposés à la grève qui occupent le prône durant ces années : Guiard de Laon qui a dû tenir son école chez les franciscains, Jean de Saint-Gilles chez les dominicains et surtout Eudes de Châteauroux qui révèle durant la grève son goût pour la prédication en remplissant non seulement son quota de sermons mais aussi celui des maîtres absents.

Alors que la grève n'en finissait pas, chacun devait essayer de deviner qu'elle serait la décision du pontife et comment gagner ses bonnes volontés. Un événement donna peut-être des

${ }^{41}$ Le meilleur récit des événements se trouve dans l'ouvrage vieilli mais solide de N. VALoIs, Guillaume d'Auvergne, évêque de Paris (1228-1249). Sa vie et ses ouvrages, Paris, 1880, p. 47-64. Plus succinct: P. Kibre, Scholarly privileges in the Middle Ages, Cambridge (Mass.), 1962, p. 92-97.

${ }^{42}$ Les contrecoups psychologiques et sociaux des grèves ecclésiastiques ont été, à notre connaissance, peu étudiés. Voir néanmoins, pour une période ultérieure, le livre suggestif de R. TREXLER, The Spiritual power : Republican Florence under Interdict, Leiden, 1974.

${ }^{43}$ M.-M. DAvy, Les sermons universitaires parisiens de 1230-1231. Contribution à l'histoire de la prédication médiévale, Paris, 1931 (les transcriptions procurées par cet ouvrage sont utiles mais malheureusement peu sûres) et en dernier lieu N. BÉRIOU, Lavènement des maîtres de la Parole,passim.

${ }^{44}$ Pour d'autres exemples voir L.-J. Bataillon, « Les crises de P'Université de Paris d'après les sermons universitaires » dans Die Auseinandersetzungen an der Pariser Universität im xiII. Jahrbundert, éd. A. Zimmermann et G. Vuillemin-Diem, Berlin - New-York, 1976, p. 155-69 (repris dans ID., La prédication au xiII siècle en France et en Italie. Études et documents, Londres, 1993).

${ }^{45}$ Voir déjà A. Callebaut, «Le sermon historique d'Eudes de Châteauroux à Paris le 18 mars 1229. Autour de lorigine de la grève universitaire et de lenseignement des mendiants ", Archivum Franciscanum Historicum 28 (1935), p. 81-114 (ici p. 96). Nous aimerions revenir sur ce point plus en détail dans une étude ultérieure. 
lumières nouvelles à la communauté des maîtres sur le caractère de Grégoire IX. En 1230, Parchevêque de Rouen, Thibaud d'Amiens meurt. Le chapitre choisit lun de ses doyens Thomas de Freauville mais lélection est contestée et portée devant Rome ${ }^{46}$. L'affaire devait être suivie attentivement par le petit monde des clercs parisiens car Thibaud était engagé dans un violent conflit avec Blanche de Castille sur des questions de juridiction et le choix de son successeur était éminemment politique ${ }^{47}$. Néanmoins, le règlement de laffaire électorale imposé par le pape est muet sur ce point. Il ne s'arrête ni sur les qualités des candidats ni sur les circonstances de lélection mais rebondit sur un argument avancé par le procureur du parti opposé à Thomas. Thomas, doyen du chapitre de Rouen cumulait des bénéfices dans des églises paroissiales. Après le concile de Latran IV, il a, de plus, obtenu un archidiaconat dans le diocèse d'Amiens, un bénéfice avec charge d'âmes, alors qu'il n'avait pas abandonné la charge des églises paroissiales. Il a ainsi contrevenu au canon De multa. Le parti en faveur de Thomas ne nie pas les faits mais présente au pape une dispense accordée sur ce point par Parchevêque de Rouen. Grégoire suit totalement largument des opposants de Thomas. Ce cumul des bénéfices est non seulement illégal mais elle est un vol (furtum vel rapinam). La dispense de larchevêque n'a aucune valeur. En mai 1230, le pape charge larchidiacre de Paris, Jean de Montmirail et Adam de Chambly, évêque de Senlis, de vérifier la véracité des faits et de s'assurer que Thomas n'a pas obtenu de dispense apostolique. Si c'est le cas, l'élection est cassée ${ }^{48}$. La bulle a dû avoir un certain retentissement dans les milieux parisiens. Jean de Montmirail et Adam de Chambly sont des personnages d'importance dans l'église capétienne. Ils sont fréquemment nommés juges délégués par les papes et souvent associés à Guillaume d'Auvergne ou avec des maîtres parisiens. Jean de Montmirail entrera par la suite chez les dominicains; il participera à la commission de condamnation du Talmud ${ }^{49}$.

Comme c'est souvent le cas au Moyen Âge, le jugement du pape ne constitua pas le mot de la fin. On négocia un arrangement afin que personne ne perde la face. Thomas renonça à son élection pour éviter l'ignominie de la cassation. L'un des prélats impliqués dans laffaire, Maurice, évêque du Mans, fut promu à larchiépiscopat de Rouen ${ }^{50}$. Thomas, bon perdant, participa à la cérémonie de remise du pallium de son adversaire ${ }^{51}$. Il gagna une place prioritaire dans le jeu de taquets des promotions épiscopales et fut élu lannée suivante évêque de Bayeux, élection confirmée par Maurice.

La bulle de Grégoire IX n'a pas ainsi brisé la carrière de Thomas. Lorsqu'elle fut connue dans les milieux parisiens dans l'été 1230, elle a dû néanmoins ouvrir les yeux de certains. Laccusation de pluralité des bénéfices était une arme efficace et le pape avait à ce sujet des positions tranchées. Dans les sermons de lautomne et de l'hiver 1230, apparaissent ainsi les premières traces que la question des bénéfices est devenue d'actualité. Dans un sermon où il traite des religieux, Guillaume d'Auvergne, jouant sur les sens multiples de claustrum (cloître

\footnotetext{
${ }^{46}$ La principale source est la Chronique de Rouen éditée dans Rec. Histor. de France, t. 23, p. 334-336.

${ }^{47}$ Sur ces conflits de juridiction peu étudiés : N. Valois, Guillaume d'Auvergne, op. cit., p. 65-83.

${ }^{48}$ Les Registres de Grégoire IX, éd. L. Auvray, Paris, 1896-1955, $\mathrm{n}^{\circ} 455$.

${ }^{49}$ Il n'existe aucune notice biographique sur ce personnage pourtant bien documenté dans les sources. Il ne faut pas le confondre avec son homonyme, saint laïc terminant sa vie comme cistercien.

${ }^{50}$ Maurice est décrit comme un prélat modèle par Thомas de Cantimpré, Bonum universale de apibus, 1.1 et 1.8 (éd. de 1605, p. 5-7; 32-33).

${ }^{51}$ La cérémonie est détaillée dans la Chronique de Saint-Ouen (Rec. Hist. France, t. 23, p. 381). Thomas y est qualifié de maître.
} 
/ resserre), dans une incise quelque peu sibylline, compare le vin qui doit être serré sous clef et les écoles qui ne doivent pas faire scandale. Scandale lorsqu'on s'y enivre et l'on provoque des rixes - allusion aux événements du bourg Saint-Marcel — ou lorsqu'on discute de prébendes ${ }^{52}$.

Cependant, c'est Guiard de Laon qui va véritablement lancer la mode. Dans son sermon pour l'Épiphanie 1231, il brode sur le thème de l'étoile qui est restée immobile au-dessus de Bethléem. Lallusion est relativement transparente même si Guiard ne l'explicite pas : les astres vagabonds se sont les maîtres et les étudiants qui ont quitté Paris alors que les mages, préfigurations de la science profane, sont allés se prosterner à Bethléem devant le Christ, c'està-dire la théologie. Les mauvais mages pour Guiard se sont d'abord les décrétistes. Mais, dans la suite de son sermon, il s'en prend à d'autres clercs ceux qui :

"Ceux qui changent leurs paroisses, disant qu'il est dangereux d'avoir une cure d'âmes, mais qui ne craignent pas d'assumer un archidiaconat alors qu'il y a là un plus grand péril et une plus grande charge d'âmes. De même, ils ne craignent pas de posséder plusieurs prébendes mais ils s'excusent en disant qu'ils y font beaucoup de fruits en y prêchant le bien c'est-à-dire en excitant les hommes aux bonnes actions. Et ceux-là ne font pas attention au fait que le préjudice qui découle d'une telle possession de prébendes est plus grand que le profit tiré du métier de prédicateur parce que nombreux sont ceux qui sont scandalisés par leur mauvais exemple. Et donc, ils ne comprennent pas qu'en matière d'actions préférables ce qui nuit le plus à un grand nombre est le moins préférable. ${ }^{53}$ ».

Lattaque s'appliquait fort bien au cas de Thomas de Freauville mais quelqu'un comme Philippe le Chancelier pouvait aussi la reprendre à son compte. Il cumulait en effet avec sa charge canoniale parisienne, un archidiaconat à Noyon et il avait lui aussi souffert des règles électorales : il était aussi candidat lors de lélection épiscopale de 1228 gagnée contre toute attente par Guillaume d'Auvergne ${ }^{54}$. Cette animosité entre le chancelier et son évêque sera lun des moteurs de la querelle parisienne sur la pluralité des bénéfices et resurgira quelques années plus tard lorsque Hugues entrera publiquement en scène.

La réponse au sermon de Guiard ne tardera pas. Le lendemain, Pierre de Bar dans son homélie lance une pique aux théologiens qui proferent des opiniones dans leurs sermons. Le

\footnotetext{
${ }^{52}$ Davy, op. cit., p. 152.

${ }^{53}$ « Tertium est quia, sicut dictum est, stella dicitur astando quia uno loco fixa est, sic religiosi et clerici fixi deberent esse ut loca sua non mutent. Unde in Ecclesiastico : Mane in loco tuo. Sed quidam sunt qui contrarium faciunt, de quibus Proverbia : Sicut avis transmutans nidos suos. Mutant enim parochias suas, dicentes quod periculosum est curam animarum habere; sed ipsi non timent accipere archidiaconatus, ubi maius est periculum et maior cura animarum. Item non timent habere plures prebendas sed excusant se dicentes quod multum fructum faciunt ibi, predicando scilicet ad bonum homines in eis movendo. Et tales non attendunt quod maius incommodum surgit ex tali possessione prebendarum quam ex officio predicationis eorum quia inde plures scandalizantur scilicet pravo exemplo eorum. Unde non intelligunt illud de eligendis quod magis pluribus nocet, minus est eligendum (cf. Aristoteles, Topica, lib. 3 cap. 3, 118b [éd. L. Minio-Paluello, Aristoteles Latinus, V, 1-3 (1975), p. 57]) ", éd. M.-M. Davy, ouvr. cité, p. 236 corrigé sur ms. Paris, BnF nouv. acq. lat. 338 , f. $94 r$.

${ }^{54}$ Sur Philippe le Chancelier voir en dernier lieu lintroduction de N. Wicki à son édition de la Summa de bono, Berne, 1985.
} 
prône n'est pas le lieu pour exposer ce que l'on doit réserver aux disputes universitaires ${ }^{55}$. Il rejoint là la position du chancelier pendant la grève. Philippe se moque avec une ironie mordante des prédicateurs parisiens qu'il compare à des petits coqs dans une basse-cour qui ne cessent de pérorer les uns contre les autres ${ }^{56}$. Dans un sermon, du début août 1231 qui annonce la fin du conflit, il répétera que les clercs ne doivent pas batailler par sermons interposés $^{57}$. Nulle part, Philippe n'endosse la légitimité de la pluralité des bénéfices. Sa ligne de défense est plus subtile. Ce qu'il sous-entend c'est que la pluralité des bénéfices est du domaine de lopinion et pas du dogme et qu'il faut respecter la multiplicité des positions à ce sujet. Néanmoins, deux ans plus tard, Philippe obtient du pape le droit de faire accomplir ses visites archidiaconales par des procureurs dominicains ou franciscains. Le pape indique dans la lettre, vraisemblablement à la requête de Philippe, que cet archidiaconat a été obtenu de manière canonique ${ }^{58}$. Deux précautions valent mieux qu'une!

Si Philippe prêche la modération en août 1231, c'est que les esprits s'étaient échauffés. Guiard de Laon a déclenché une vague d'attaques contre le pluralisme. Le dimanche suivant Pépiphanie, Jean de Saint-Gilles va longuement revenir sur les maux qui accablent selon lui P'Université et P'Église. Il attaque l'absentéisme, linstitution des vicaires et la pluralité des bénéfices. Le régime des études est aussi à réformer : les étudiants font des études trop longues, ils s'intéressent trop à la philosophie et s'orientent vers les sciences lucratives aux dépens de la théologie ${ }^{59}$. Eudes de Châteauroux va consacrer un sermon à essayer de prouver que la minorité a quelquefois raison contre la majorité. Il brode autour de la figure d'Ephraïm, le cadet, choisi par Israël de préférence à son frère aîné, Manassé (Gn 48). La descendance d'Ephraïm mentionnée par la Bible ce sont les clercs mais leur majorité ne tient pas à leur nature mais,

\footnotetext{
${ }^{55}$ "Sed sunt quidam theologi nostri qui mansuetudinem intellectus nolentes offerre, opiniones in sermonibus suis recitant et in disputationibus suis recitant affectiones, cum potius faciendum esset e contrario » (éd. DAvY, p. 253).

${ }^{56}$ « Mirum est igitur, quod tot dormiunt Parisiis in peccatis, quia in nulla villa campestri tot sunt galli quot Parisiis predicatores et doctores. Sed forsitan ex hoc contigit, quod qui esse deberent precones diei et excitare dormientes facti sunt galli pugnaces. Quid enim est ista contentio doctorum nisi pugnam gallorum? Pueri facti sumus, qui nihil aliud facimus nisi pugnam gallorum. Unde ridiculum facti sumus laicorum. Gallus insurgit contra gallum et eristatur contra eum [...] sic hodie magister contra magistrum et sese ad invicem corrodunt ", ms. Paris, BnF, lat. 3280, f. 1v (d'après J. B. Schneyer, Die Sittenkritik in den Predigten Phillips des Kanzlers, Münster, 1963, p. 89). Philippe tente de résoudre le conflit en s'appuyant sur une logique segmentariste. Le combat entre deux partis cléricaux est neutralisé en invoquant un ennemi commun d'un niveau supérieur contre lequel les deux groupes doivent être unis. Ici, les factions de maîtres doivent tenir un front commun contre les laïcs. Sur la fréquence de ce mode de raisonnement dans le monde clérical médiéval voir A. Boureau, La Loi du Royaume. Les moines, le droit et la construction de la nation anglaise ( $\mathrm{xI}^{e}-\mathrm{xIII}^{e}$ s.), Paris, 2001.

${ }^{57}$ « Mirum est enim quomodo predicatores nostri, opiniones veras esse asserendo, audent in predicationibus suis discordare. Unde Job, XXXVIII : Numquid coniungere poteres micantes stellas Pleiadas aut gyrum Arcturi poteris dissipare? (Job. 38.31) Per septem Pleiadas significatur universitas clericorum qui, licet divisi sint gradu, officio, dignitate, patria, regione, tamen conformitate caritatis debent esse coniuncti [...].Sed hodie febricitat Ecclesia ex inequalitate humorum, id est clericorum : hodie enim socrus Simonis, id est scientia predicationis, febricitat febre dissenssionis et discordie, sed stans Jesus super eam imperavit febri et sanata est (Luc 4.39) Cogitetur ergo Jesus, etc. Deliberatio habeatur et cessabit ista discordia quia ut dicitur ad Corinthios : Deus autem non est Deus dissensionis sed auctor pacis (1 Cor. 14.33)»(DAvy, op. cit., p. 165). La deliberatio à laquelle Philippe fait allusion est vraisemblablement la bulle Parens Scientiarum.

${ }^{58}$ H. Denifle et E. Chatelain, éd., Chartularium Universitatis Parisiensis [désormais CUP], t. I, Paris, 1889, $\mathrm{n}^{\circ} 98$.

${ }^{59}$ DAvy, op. cit., p. 289-292.
} 
comme pour Ephraïm, à leur vertu. Or, parmi cette descendance, il y a des monstres comme ceux qui cumulent les prébendes. Il leur sera appliqué la parabole évangélique sur larbre sans fruits qui sera arraché et brûlé (Mt 7.19). Avec humour, Eudes ajoute que ce verset biblique n'est pas glosé par Pindication : « sauf dispense du Seigneur ». Le maître termine son sermon en attaquant ceux — c'est-à-dire Pierre de Bar et derrière lui Philippe le Chancelier - qui disent que l'on ne peut avoir sur le sujet de la pluralité des prébendes que de simples opinions ${ }^{60}$. Philippe, prieur de Saint-Jacques, différents dominicains anonymes et Eudes de Châteauroux, à nouveau, prêcheront aussi violemment contre la pluralité ${ }^{61}$. Les franciscains resteront plus en retrait ${ }^{62}$. Les attaques sont certainement concertées et paraissent téléguidées. Ainsi, le 9 février Eudes de Châteauroux se rend à Saint-Jacques pour prêcher le premier dimanche de Carême. A la fin de son sermon, alors qu'il n'en avait dit mot auparavant, il attaque de manière incidente les pluralistes; un morceau convenu pour un public conquis d'avance ${ }^{63}$. La coordination entre les différents prédicateurs se remarque aussi par le fait qu'ils partagent un même stock de références bibliques. Lorsque Moïse est parti sur la montagne, il a laissé à la garde d'Aaron le peuple juif, qui s'est empressé d'adorer le veau d'or ${ }^{64}$. Voilà ce qui arrive lorsqu'on laisse son église à un vicaire. Une deuxième référence commune est plus recherchée. Les prédicateurs utilisent certains versets de la prophétie d'Habaquq dans laquelle ils croient trouver une critique du pluralisme ${ }^{65}$.

La campagne de ce groupe de prédicateurs parisiens anti-pluralistes s'essouffle au début juin 1231. La bulle Parens Scientiarum est envoyée par la chancellerie pontificale à la mi-avril et a dû arriver à Paris un mois plus tard. Le conflit était fini. Cependant, on aurait tort de penser que la tempête ne dépassa pas le verre d'eau cerclée par les murailles parisiennes. L'Église anglaise, saturée de maîtres et d'étudiants formés à Paris, réagit immédiatement aux modifications

\footnotetext{
${ }^{60}$ " Unde liquidum est quod nobis et religiosis convenit verbum istud sed prius dicamus de nobis scolaribus. Effraym etc. interpretatur auctus etc. et significat clericos qui maiores aliis sunt [...] aucti dicuntur illi qui sunt indurati hodie quod ex eis non potest homo fieri sicut ex Adam facta est Eva in Gen. Sunt enim aridi et sicci ab humore gratie. [...] Et sic dictum est Effraym interpretatur crementum. Crementum autem in moribus attenditur in diviciis, prebendis, honoribus et huiusmodi et sicut est in naturis quod ex cremento provenit menstruositas (sic) scilicet plures manus aut digiti sex vel septem aut duo capita, aut huiusmodi sic etiam est in moribus excremento menstruositas scilicet ut homo duo capita habeat aut duas dignitates aut plures prebendas. [...] Sed timeat talis quod de hoc in alio evangelio impletur ubi dicitur omnia arbor que non fecerit fructum bonum exudetur et in ignem mittetur non invenitur ibi aliqua glosa que dicat : 'nisi dispensatum fuerit ei a Domino'. Sed dicet aliquis : 'ego fructum facio, bona enim ecclesie in bonos usus expendo et vivo in scolis et huiusmodi'. Sed istud non sufficit. Impossibile est enim quod arbor in alio loco quam in illo in quo plantata est possit fructificare. [...] Hec itaque crementum multas deformitates generat in Ecclesia Dei unde de auctis qui scilicet sicut provectorius etatis vere potest dici Effraym quasi scopulus durissimus. Quia tales statum suum non mutantes faciunt sibi perizomata, latentes in umbra sacre scripture, licet sit contra conscientiam eorum et inde accidit quod illud quod certum est, opinionem reputant, scilicet habere plures prebendas, unde istud non debet predicari ", ms. Paris, BnF, nouv. acq. lat. 338, f. 107v $\mathrm{v}^{\circ}-109 \mathrm{r}^{\circ}$. Sur Eudes de Châteauroux voir en dernier lieu A. Charansonnet, « Du Berry en Curie, la carrière du cardinal Eudes de Châteauroux (1190? 1273 ) et son reflet dans sa prédication ", Revue d'hist. de l'Église de France, 86 (2000), p. 5-37.

${ }^{61}$ Philippe le Prieur (Davy, op. cit., p. 307 et 314); dominicains anonymes (Ibid., p. 342) et le sermon anonyme (Ibid. p. 412). Eudes de Châteauroux (Ibid., p. 212 et HaurÉAu, Notices et extraits..., t. VI, p. 216).

${ }^{62}$ Voir néanmoins Jean de Blois (Davy, op. cit., p. 374).

${ }^{63}$ Davy, op. cit., p. 265 sous le nom d'Étienne de Châlons.

${ }^{64}$ Ex. 32 (DAvy, op. cit., p. 289 et 374).

${ }^{65}$ Ibid., p. 307 et 412.
} 
de lopinion intellectuelle. On ne peut savoir le degré de connaissance qu'Hugues avait de Pactualité anglaise. Cependant, les réseaux dominicains et universitaires unissent fortement les deux côtés de la Manche et le maître régent ne fut certainement pas étranger aux affaires qui secouaient le puissant siège de Cantorbéry.

\section{LE BASCULEMENT DE L'OPINION PUBLIQUE ANGLAISE}

Durant l'automne et l'hiver 1231-1232, l'Angleterre fut agitée par un mouvement xénophobe dirigé contre les clercs italiens qui avaient reçu des prébendes dans les églises locales. Une bande armée dirigée par un petit noble rançonna des clercs italiens et mit à sac leurs propriétés ${ }^{66}$. Ces troubles ne sont pas totalement spontanés mais soutenus en sous-main par Hubert de Burgh, justicier du royaume dont le pouvoir vacille. Du reste, lorsque, après une révolution de palais, Édouard III et le nouvel homme fort du régime, Pierre des Roches, commencèrent la répression à la requête pressante du pape, ils se servirent des mandements pontificaux pour asseoir leur conquête et frapper les réseaux du justicier ${ }^{67}$. L'exaspération contre les clercs étrangers fit long feu. Cependant, au-delà de ces implications dans la politique locale et dans la construction de lidentité anglicane, laffaire de 1231 témoigne d'un basculement dans lopinion publique anglaise.

Après 1231, on peut parler d'une question bénéficiale en Angleterre. Il faut s'empresser d'ajouter que dans le détail, les positions et les niveaux de compréhension sont très variés. Pour les nobles, il s'agit seulement de défendre leur droit de patronage contre les empiétements des pouvoirs ecclésiastiques ainsi que de sauvegarder les réseaux locaux de promotion cléricale.

Les récriminations contre les clercs étrangers ne sont pas propres à l'Angleterre. Elles vont traverser la Manche et se retrouveront dans le vigoureux mémoire adressé en 1247 par saint Louis à Innocent $\mathrm{IV}^{68}$. Pour les clercs issus des universités, les lignes de fracture entre les rigoristes et les autres se situent sur un plan plus juridique. Elles deviennent brusquement apparentes non seulement sous linfluence des débats parisiens mais aussi parce que l'Église anglaise traverse une période de crise ${ }^{69}$. De 1231 à 1233 , le siège de Cantorbéry reste vacant. Deux candidats élus par les moines de Christchurch pour plaire à Hubert de Burgh sont invalidés l'un après lautre par la curie à linstigation d'un des hommes forts du clergé anglais, Simon de Langton, archidiacre de Cantorbéry et frère de feu Parchevêque Étienne. Lorsque Pierre des Roches arrive au pouvoir, il fait élire et accepter par le roi un troisième homme, Pun de ses alliés, John Blund. Ce maître ès arts à Paris fut l'un des grévistes qui quittèrent la capitale capétienne en 1229. A nouveau laffaire est envoyée devant le pape pour obtenir la confirmation de l'élection mais un parti opposé à John Blund se forme dont lâme est vraisemblablement encore Simon Langton. Largument des opposants au nouvel archevêque-élu est le même que celui utilisé pour l'élection de Thomas de Freauville; John Blund est plura-

\footnotetext{
${ }^{66} \mathrm{H}$. McKenzIE, «Anti-Foreign Movement in England, 1231-1232 », dans Anniversary Essays in Mediaeval History by students of Charles Homer Haskins presented on his completion of forty years of teaching, éd. C. H. TAYLOR et J. L. La Monte, Boston, 1929, p. 183-203.

${ }^{67}$ N. Vincent, Peter des Roches. An Alien in English Politics, 1205-1238, Cambridge, 1996, p. 303-309.

${ }^{68}$ J. Le GofF, Saint Louis, Paris, 1996, p. 783-85.

${ }^{69}$ L'affaire est racontée en détail par N. VINCENT, ouvr. cité.
} 
liste et n'a pas de dispense pontificale. La cause est suivie du même effet. Grégoire IX casse Pélection et demande aux procureurs de lui suggérer un nouveau candidat. Ils proposent Edmond Rich, un autre maître ès arts, le champion du parti conservateur dans ses choix intellectuels, réformateur dans sa politique pastorale, défenseur d'une séparation nette entre église et couronne et, comme nous l'avons vu, anti-pluraliste ${ }^{70}$. L'élection d'Edmond n'était pas du goût de tous et certains clercs anglais de retour de Rome à Cantorbéry, faisant halte à Andres, abbaye proche de Calais, s'en ouvrirent au chroniqueur du monastère, lui racontant que John Blund avait été rejeté pour des broutilles $\left(\right.$ frivolitas) ${ }^{71}$. Pour d'autres, à limage d'Edmond Rich, le pluralisme devient une question de principe. C'est le cas de Robert Grosseteste qui, au sortir d'une maladie et d'une crise de conscience, abandonne volontairement en 1232 tous ses bénéfices sinon un ${ }^{72}$. Dans une missive à son ami Adam de Marisco, il explique que cet acte d'obéissance aux constitutions pontificales lui a valu des attaques et du mépris, même de proches. Dans une veine similaire aux sermons anti-pluralistes parisiens, Robert explique que son engagement dans la pastorale exigeait ce dépouillement ${ }^{73}$.

\section{La Simonie dans le Scriptum d'Hugues de Saint-Cher}

Dans les mêmes années où la pluralité des bénéfices rentre sur le devant de la scène parisienne et anglaise, Hugues de Saint-Cher rédige son commentaire sur les Sentences, connu sous le titre de Scriptum. On n'y trouve malheureusement aucune référence à la question. Ceci n'est, malgré tout, pas étonnant. Le Scriptum est un assemblage des travaux des théologiens en vogue lors des études d'Hugues. Le chapitre sur la simonie reprend à plus de $75 \%$ la Glose sur les Sentences d'Alexandre de Halès, la Summa Aurea de Guillaume d'Auxerre et la Somme sur les Sacrements de Guy d'Orchelles ${ }^{74}$. Les développements des maitres parisiens des années 1220 qu'Hugues de Saint-Cher reprend sont eux-mêmes des adaptations de la doctrine canonique du début du xıII ${ }^{\mathrm{e}}$ siècle. La simonie avait constitué un débat brûlant durant tout le $\mathrm{XII}^{\mathrm{e}}$ siècle et n'avait été que progressivement déminée. À partir du XIII ${ }^{\mathrm{e}}$ siècle, les intellectuels trouvent de nombreuses justifications aux échanges économiques au sein de l'Église. Hugues de Saint-Cher se demande ainsi si l'on peut prêcher en vue d'obtenir des biens terrestres. Il répond que cela est licite car la prédication a pour première conséquence d'exciter la piété des auditeurs. C'est cette piété qui va, dans un deuxième temps, pousser les fidèles à donner de largent. Le don est une causalité secondaire et non pas principale de la prédication et laction n'est donc pas simoniaque. Cette distinction logique des causalités principales et secondaires qui se fonde sur une distinction des significations de la proposition pro permet de bâtir un système très permissif qui réduit à peu de cas les activités simoniaques. On peut arguer que tout acte ecclésiastique a pour fin principale et ultime Dieu. Ce qui permet, en retour, de justifier tous les trafics économiques. Hugues de Saint-Cher reprend la question

\footnotetext{
${ }^{70}$ Le zèle d'Edmond devra du reste être tempéré par Grégoire IX dans une lettre de 1235 (éd. W. WAdDington Shirley, Royal and Other Historical Letters Illustrative of the Reign of Henry III, Londres, 1862 [" Rolls Series" 27], t. I, p. 558-59).

${ }^{71} \mathrm{MGH}$, Scriptores, t. XXIV, p. 772.

${ }^{72}$ Epistolae, n. 8 (éd. citée, p. 43-44).

${ }^{73}$ Epistolae, n. 9 (éd. citée, p. 45-47).

${ }^{74}$ Voir ci-après lannexe « Hugues de Saint-Cher était-il juriste? »
} 
et la solution à Guillaume d'Auxerre ${ }^{75}$. Son intervention se limite à lajout de deux citations bibliques supplémentaires, des versets bibliques courants dans un tel contexte. Le raisonnement de Guillaume est élégant et efficace. Il n'en reste pas moins étonnant qu'Hugues l'endosse si facilement. Voilà des positions qui s'accordent avec les objectifs d'un grand prélat mais semblent peu compatibles avec le projet mendiant.

Le Scriptum montre ainsi un théologien peu révolutionnaire sur les questions de morale de l'Église et qui tient des positions modérées sur les liens entre argent et religion. On n'y trouve aucun passage sur le pluralisme. Pourtant, Hugues a enseigné lors de la crise de 123031 et il a certainement assisté aux sermons vilipendant le cumul. Il est évidemment difficile d'expliquer les raisons de ce silence. On peut du reste s'en tenir à la logique de composition du Scriptum. Le commentaire d'Hugues a pour ambition d'être un compendium de quelques œuvres théologiques récentes. Or, ni Alexandre de Halès, ni Guillaume d'Auxerre, ni Guy d'Orchelles ne parlent de pluralisme. D'autre part, Hugues, praticien du droit et non pas canoniste, n'avait certainement pas à lépoque de connaissance directe des débats bolonais autour du canon De multa ${ }^{76}$. Quelles que soient ses positions sur le sujet, il n'avait pas encore les matériaux nécessaires pour bâtir son opinion de maître en théologie.

\section{LES QUESTIONS DISPUTÉES DE I 235-I 242}

C'est dans la deuxième phase de la dispute qu'Hugues prendra une place de premier plan. En 1234, Grégoire IX publie le Liber Extra. Le pape envoie un exemplaire du nouveau code législatif aux universités de Bologne et de Paris en Paccompagnant de la bulle Rex Pacificus qui ne laisse aucun doute sur la valeur normative de cette nouvelle collection. On y trouvait en particulier différents textes sur le pluralisme et en particulier le canon de Latran IV, De multa.

Peu après la publication du Liber Extra, la querelle sur la pluralité renaît. Nous avons la chance de posséder une source narrative sur cet épisode : le récit que donne Thomas de Cantimpré dans son Bonum universale de apibus :

Je veux que tous mes lecteurs sachent qu'en lan de l'Incarnation du Seigneur 1238 je me trouvais à Paris au moment où le vénérable Guillaume, évêque de Paris, qui avait auparavant exercé la maîtrise en théologie, convoqua une assemblée générale de tous les maîtres au chapitre des frères prêcheurs. Il proposa le problème (questio) de la pluralité des bénéfices et au terme d'une disputatio savante et prolongée, il fut établi (determinatio) qu'on ne pouvait sans mettre en danger le salut de son âme détenir deux bénéfices, dès que l’un deux valait quinze livres parisis. C'est le susdit évêque qui fit cette détermination (determinare). Plus tard le frère Hugues de lordre des prêcheurs, puis cardinal de la curie romaine, les frères Guerric $<$ de Saint-Quentin $>$ et Geoffroy $<$ de Bléneau $>$ du même ordre, frère Jean de La Rochelle, de lordre des frères mineurs et beaucoup d'autres maîtres en théologie firent la même détermination dans leurs écoles. Il y avait d'ailleurs eu trois

\footnotetext{
${ }^{75}$ Guillaume D’Auxerre, Summa Aurea, liber tercius, pars II, 18.2, éd. J. Ribailler, Paris / Grotaferrata, 1980-87, p. 942-43.

${ }^{76}$ Voir PAnnexe : « Hugues de Saint-Cher était-il juriste? ».
} 
ans auparavant une autre discussion (disputatio) très longue et beaucoup plus solennelle, dans laquelle il est avéré que tous les maîtres en théologie, sauf deux, déterminèrent tout à fait dans le même sens que ci-dessus. Les deux exceptions étaient celles de Philippe, chancelier de Paris, et maître Arnould, plus tard évêque d'Amiens.

Écoutons maintenant ce qui est arrivé à ce Philippe. Il était agonisant, proche de la mort, quand le susdit Guillaume, évêque de Paris, vint le visiter; il lui demanda de renoncer à son opinion singulière sur la pluralité des bénéfices et de résigner des bénéfices et de résigner entre les mains de l'Église tous ses bénéfices à l'exception d'un seul. Il ajoutait même, à titre de compensation, qu'en cas de guérison, lui, l'évêque, suppléerait sur ses biens propres à la perte ainsi subie par le chancelier. Ce dernier refusa, disant qu'il voulait savoir par expérience si c'était vraiment un cas de damnation de détenir plusieurs bénéfices ${ }^{77}$.

Il meurt quelques jours plus tard et apparaît alors à Guillaume son fantôme qui lui avoue qu'il est damné, en particulier pour n'avoir pas renoncé à ses multiples bénéfices. Thomas termine son histoire en disant que Guillaume « raconta souvent ce fait dans ses prédications à son clergé - mais pourtant sans se mettre en scène, comme s'il en avait été témoin. »

Ce texte est célèbre. Déjà, il captivait les médiévaux qui lont inclus dans des collections d'exempla ou qui lont fait circuler indépendamment du Bonum universale de apibus ${ }^{78}$. Pourtant, même si Thomas a été témoin de laffaire, son récit doit être lu cum grano salis. Il écrit sa version des faits après 1256 , plus de vingt années après les événements. Or, depuis les années 1250, les rapports entre les dominicains parisiens et la communauté des maîtres séculiers ont tourné au vinaigre, alors qu'en 1235, les tensions entre les mendiants et les séculiers n'apparaissent pas encore. Rien ne prouve que Philippe le Chancelier ait eu le rôle noir que Thomas lui donnele tigre well ${ }^{79}$. On peut aussi s'interroger sur limplication de Jean de la Rochelle. Le maître franciscain a peut-être déterminé oralement mais ce fut alors du bout des lèvres. On ne trouve ainsi aucun écho du débat sur la pluralité dans les œuvres franciscaines contempo-

\footnotetext{
${ }^{77}$ Thomas de Cantimpré, Bonum Universale de apibus, 1.19.5-6, voir aussi 2.10.36. Nous reprenons la traduction d'H. Platelle, Thomas de Cantimpré, Les exemples du Livre des abeilles, Turnhout, 1997, p. 83-84 et p. 13132. Contrairement à ce qu'écrit A. G. Traver, « Rewriting History? The Parisian Secular Masters' Apologia of 1254 ", History of Universities, 15 (1997-99), p. 9-45, ici p. 33-34, les documents ou descriptions de l'affaire publiés par les historiens de l'Université de Paris (C. E. Du Boulay, Historia Universitatis Parisiensis, t. III (1666), p. 154-55; C. Du Plessis D’Argentré, Collectio Iudiciorum de novis erroribus, t. I (1728), p. 143-44 et CUP, t. I, $\left.\mathrm{n}^{\circ} 108\right)$ ne puisent qu'à une seule et même source, Thomas de Cantimpré.

${ }^{78}$ Pour les recueils d'exempla : le texte de Thomas se retrouve dans le ms. Londres, British Library, Royal 7 D I, f. 136v (transcrit dans les papiers Welter conservés à la BnF) dans le Speculum laicorum (éd. J.-Th. Welter, 1914, p. 305) et dans le Magnum speculum exemplorum (éd. Major, 1611) aux rubriques beneficium et infernus. Nous devons ces renseignements à Marie Anne Polo de Beaulieu qui travaille à la réalisation de la base de données exempla. D’autres références dans J. B. SCHNEYER, "Entstehung und Überlieferung eines mittelalterlichen Predigtexempels », Theologische Quartalschrift, 146 (1966), p. 329-347. Ce passage du Bonum universale de apibus a aussi circulé de manière indépendante. D'après la base de données In principio, on le retrouve dans trois manuscrits du xv ${ }^{\mathrm{e}}$ siècle, Klosterneuburg, Stiftsbibl., 230b, f. 1 et Prague, Bibl. Univ., 1510 en tête d'un Tractatus de pluralitate beneficiorum cum addimentis variis vitam clericorum et ecclesie statum concernentibus et Londres, British Library, Royal 6 E III, n. 21.

${ }^{79}$ R. Lerner, "Weltklerus und religiöse Bewegung im 13. Jahrhundert », Archiv für Kulturgeschichte, 51 (1969), p. 94-108.
} 
raines que ce soit dans le travail collectif qu'est la Summa fratris Alexandri ou dans la Summa de vitiis de Jean de la Rochelle ${ }^{80}$. Enfin, la position personnelle de Thomas de Cantimpré est celle d'un extrémiste. Il rapporte dans son Bonum universale de apibus des paroles de Grégoire IX, très certainement apocryphes, selon lesquelles le pape ne peut dispenser de par sa plenitudo potestatis le cumul mais simplement dispenser les pluralistes des poursuites judiciaires ${ }^{81}$.

Si lon suit le récit du dominicain, la chronologie des questions disputées se déroule en trois phases. En 1235, a lieu la première dispute longue et solennelle où les maîtres des différentes écoles déterminèrent contre la pluralité des bénéfices, à Pexception de Philippe le Chancelier et d'Arnould de La Pierre. La chronologie de cette première phase est corroborée par la mort de Philippe le Chancelier à la fin 1236, année qui est aussi celle de lélévation d'Arnould à Pépiscopat. Dans un deuxième temps, en 1238, Guillaume d'Auvergne rassemble les maîtres au chapitre des prêcheurs. Il se déroule une nouvelle dispute. Ce sont vraisemblablement des dominicains qui assurent les fonctions d'opponens et de respondens ${ }^{82}$. Guillaume détermine. Dans un troisième temps, Hugues de Saint-Cher conduit une nouvelle question disputée ainsi que Guerric de Saint-Quentin et Geoffroy de Bléneau. Jean de la Rochelle détermine aussi pour les franciscains.

Quand ont lieu ces nouvelles disputes? Se déroulent-elles dans la foulée de lassemblée de 1238 ou dans les années qui suivent? L'organisation institutionnelle de ces disputes à SaintJacques pose aussi problème. Depuis, 1236, Hugues est à nouveau provincial de France et il a abandonné la régence en théologie. Les régents dominicains jusqu'à lannée scolaire 124142 sont Guéric et Geoffroy. Hugues, reprenant temporairement son précédent statut, a-t-il disputé avec Guéric et Geoffroy comme opponens et respondens? Ou bien, les trois maîtres dominicains ont-ils disputé à tour à tour? Thomas de Cantimpré n'indique pas en tout cas qu'il a assisté aux nouvelles disputes dominicaines. Il emploie une formule temporelle vague qui pourrait signifier que cette troisième phase doit être placée après son départ de Paris à lautomne $1240^{83}$. Du reste, hormis le texte de Thomas, il n'existe aucun élément pour faire débuter la régence de Jean de la Rochelle en 1238 et pas en 1241. En résumé, le témoignage de Thomas paraît indiquer que la première phase se déroule durant lannée scolaire 1235, la deuxième en 1238 et la troisième durant les années scolaires 1240-42.

Les questions disputées de 1235-36 ne sont pas nées de manière spontanée. Nous avons quelques indices qu'une nouvelle bataille par sermons interposés faisait rage à Pépoque. Le Commentaire dominicain moral sur l'Apocalypse Aser cum pinguis écrit dans ces années raille « ceux qui prêchent en vulgaire le vendredi » en faveur du pluralisme. Surtout, Guillaume

\footnotetext{
${ }^{80}$ Summa fratris Alexandri, éd. Quaracchi, 1928-1948. Pour la Summa de vitiis, nous avons parcouru le ms. Paris, BnF, lat. 16417.

${ }^{81}$ «Cum beatissimus memorie papa Gregorius Nonus interrogaretur, si posset de plenitudine potestatis cum plurium beneficiorum detentoribus dispensare, respondit : non possum inquit, nisi tantum super vexatione detinencium dispensare ", ms. Paris, BnF, lat. 3309, f. 15rb (cité d’après E. Berger, Saint Louis et Innocent IV, Paris, 1893, p. 288, n. 2).

${ }^{82}$ Une question disputée comporte quatre éléments : 1 . l'énoncé de la question; 2 . les arguments pro et contra 3. la détermination; 4 . les réponses aux contra, les ad obiecta. Le maître est responsable du 1. du 3. et d'une partie du 4. L'opponens fournit les contra du 2. Le respondens se charge du 4. cf. J.P Torrell, Théorie de la prophétie et philosophie de la connaissance aux environs de 1230. La contribution d'Hugues de Saint-Cher, Louvain, 1977.

${ }^{83}$ H. Platelle, op. cit., p. 16.
} 
d'Auvergne a prononcé des sermons violents contre le cumul ${ }^{84}$. L'évêque de Paris rédige enfin un traité sur la collation des bénéficesle tigre well ${ }^{85}$. Ce texte quelque peu étrange ne peut se comprendre que si on le replace dans son contexte institutionnel. Un évêque au Moyen Âge a relativement peu de pouvoir sur le choix des bénéficiers de son diocèse. Sa tâche est simplement de contrôler que le candidat présenté par le patron possède les aptitudes nécessaires pour sa tâche (ordre ecclésiastique, éducation, régularité de la personne). Certains évêques se sentent bridés par ces règles qui limitent leur action réformatrice. Afin d'avoir les coudées franches, ils développent une idéologie d'une monarchie épiscopale décalquée des élaborations politiques de la monarchie pontificale. Au sein de son diocèse, l'évêque a la plenitudo potestas, un pouvoir éminent sur toutes les matières peccamineuses. Il doit pouvoir contrôler régulièrement les communautés religieuses, surveiller les clercs, vérifier l'orthodoxie de tous. L'un des héros du monarchisme épiscopal est Robert Grosseteste qui écrira plusieurs traités à ce sujet. Il tentera dans son diocèse de Lincoln de s'attaquer à lindépendance de son chapitre et fera passer de terribles examens aux candidats aux bénéfices ${ }^{86}$. Le De collatione beneficiorum participe du même mouvement. Guillaume d'Auvergne est un écrivain confus et il est bien difficile de tracer les lignes de force de Pensemble mais le but qu'il poursuit consiste à placer la collation sur un plan uniquement moral. Le délicat équilibre des pouvoirs entre le collateur ordinaire, le collateur extraordinaire, et l'ordinaire du lieu est laissé de côté. L'évêque de Paris n'en dit mot tout à sa flamme d'expliquer que ce sont des critères strictement moraux qui doivent conduire les prélats à choisir les plus dignes. Les normes de linstitution ne sont d'aucune importance. Quelques principes moraux, appuyés sur l'Écriture et la théologie, doivent régler l'ensemble et permettre de balayer les mauvaises coutumes. Guillaume en vient même à mettre en doute la liberté pontificale de dispense. Il a bien reçu des dispenses de pluralisme provenant du Saint-Siège, mais il les a gardées par-devers lui car, selon lui, elles ne valent rien. Le pape ne peut dispenser de lavarice, de la cupidité et de lambition ${ }^{87}$. L'Église devrait s'organiser selon une ecclésiologie hiérarchique d'inspiration dionysienne qui ne laisse aucune place ni à des îlots indépendants, ni à des relations directes entre le sommet et la base.

Les rêves du théologien Guillaume se sont certainement brisés sur la dure réalité de ladministration épiscopale. Les actes de lévêque montrent que les droits de collation restent âprement partagés et qu'il n'acquiert pas ce pouvoir supérieur de contrôle qu'il espérait ${ }^{88}$.

\footnotetext{
${ }^{84}$ Pour ce commentaire sur l'Apocalypse et sur les indices de la prédication de Guillaume, voir l'Annexe : «Le dossier des textes de la querelle de 1235-1238 ». On trouve aussi des sermons d'Eudes de Châteauroux, en dehors de la période de la grève, qui attaquent le pluralisme (Charansonnet, op. cit., p. 25, n. 72).

${ }^{85}$ Guillaume D’Auvergne, De collatione beneficiorum (Opera Omnia, Paris / Orléans, 1671, t. 2, p. 248-260).

${ }^{86}$ W. A. Pantin, "Grosseteste's Relations with the Papacy and the Crown », dans Robert Grosseteste. Scholar and Bishop, éd. D. A. Callus, Oxford, 1955, p. 178-215.

${ }^{87}$ Guillaume D’Auvergne, De collatione beneficiorum, éd. citée, p. 260 : «Quod si abiecerit nobis de dispensationibus Apostolicis. Respondemus quod ille supra nos sunt et quod diligentius considerate irrite sunt, et de omni dispensatione facta idem sentimus nec interpretari presumimus. Econtrario tamen indubitanter sciendum est quod Romanus Pontifex quantumcumque largam dispensationis gratiam videatur facere in beneficiis cum aliquibus personis; tamen non dispensat cum avaritia, cupiditate, vel ambitione earum, nec indulget eis indulgentiis suis, et his vel aliis vitiis : non enim intendit pascere vel nutrire pestes vitiorum de bonis temporalibus ecclesiasticis que plene novit ad sustentationem servorum Dei in eius servitio certificata esse domino, et ablata ".

${ }^{88}$ Voir par exemple le règlement en 1228 d'une dispute sur des questions de collation entre lévêque et le chapitre de Saint-Germain-l'Auxerrois (M. Guérard, Cartulaire de l'Église Notre-Dame de Paris, Paris, 1850, t. 1, p. 126-
} 
La lutte de Guillaume contre le pluralisme doit pourtant s’apprécier à laune de ses idéaux de monarchisme épiscopale. Les sermons qu'il prononce, le traité qu'il rédige, la détermination qu'il donne lors de la dispute solennelle de 1238 le placent dans une position hybride de théologien et d'évêque. Après avoir connu de sérieux revers politiques au début de son épiscopat, il tente d'obliger P'Université à construire une norme qui appuierait ses propres efforts de reconquête du pouvoir. Contrairement à ce que laisse entendre le récit de Thomas de Cantimpré, c'est vraisemblablement Guillaume d'Auvergne qui a eu Pinitiative de rouvrir la querelle. Les dominicains ont peut-être été instrumentalisés.

\section{LA POSITION DE L'ORDRE DOMINICAIN SUR LA PLURALITÉ DES BÉNÉFICES}

En effet, à lire le récit de Thomas de Cantimpré, on pourrait penser que la lutte contre la pluralité des bénéfices faisait partie du programme de l'ordre dominicain dans les années 1230-40. C'est loin d'être le cas. L'ordre est jeune. Son identité est en formation. Les frères se sont convertis déjà formés, avec leurs idées et leurs marottes. Sur des sujets brûlants d'actualité, comme les rapports entre philosophie et théologie ou les problèmes de morale ecclésiastique, les grands projets de compilation menés à Saint-Jacques (Speculum, Postilles) sont traversés de courants contraires et incompatibles qui opposent anciens et modernes, révolutionnaires et conservateurs ${ }^{89}$. Hugues de Saint-Cher lui-même a pu donner des signes de cette schizophrénie. On connaît un sermon de lui où il attaque lamour de largent des clercs et critique de manière virulente les maîtres ès arts et en théologie ${ }^{90}$. Or, tant son utilisation de la philosophie que son traitement de la simonie ainsi que les déterminations des questions disputées révèlent un caractère essentiellement modérée ${ }^{91}$.

Un rapide parcours des Postilles placées sous lautorité d'Hugues de Saint-Cher montre les degrés variés de l'opposition au pluralisme parmi les dominicains ${ }^{92}$. Dans le Commentaire sur les Psaumes, le traitement de la question des prébendes est ainsi relativement conventionnel. Le psalmiste parle du " peuple de vaches tentées par largent ». L'exégète propose de voir dans ces vaches ceux qui possèdent de grasses prébendes ${ }^{93}$. Quelques feuillets plus

28).

${ }^{89}$ Sur les courants pro- et anti-philosophiques dans le Speculum : M. PAulmier-FoucART, «Les protecteurs séculiers de Vincent de Beauvais » dans Lector et compilator. Vincent de Beauvais, frère prêcheur. Un intellectuel et son milieu au xiıı siècle, éd. S. Lusignan et M. Paulmier-Foucart, Grâne, 1997, p. 215-231. Certains maîtres dominicains restèrent fidèles à une théologie augustinienne opposée à Aristote. Voir les remarques sur Guillaume Luxi de L.-J. Bataillon, "De la lectio à la praedicatio. Commentaires bibliques et sermons au xim ${ }^{\mathrm{e}}$ siècle ", Revue des Sciences philosophiques et théologiques, 70 (1986), p. 559-574 (repris dans ID., La prédication au XIII ${ }^{\mathrm{E}}$ siècle en France et en Italie, Variorum, 1993), ici p. 570 et « Les crises de l'Université de Paris d'après les sermons universitaires ", op. cit., p. 167-68.

${ }^{90}$ Sermon dans loctave de l'Ascension, Bruxelles, Bibl. Roy., II.1147, f. 88ra-vb cité par L.-J. BATAILlon, « Lectio et Praedicatio ... ", op. cit., p. 569, n. 50

${ }^{91}$ Sur Hugues de Saint-Cher et la philosophie cf. L.-J. BAtaillon, « L'activité intellectuelle des Dominicains de la première génération " in S. Lusignan et M. Paulmier-Foucart, Lector et compilator, op. cit., p. 9-19, ici p. 18 n. 16. Hugues, en tant que théologien, est très dépendant de Guillaume d'Auxerre, grand introducteur du nouvel Aristote à Paris.

${ }^{92}$ La Postille sur Habaquq ne comporte pas d'allusion au pluralisme alors que ce texte avait été utilisé dans la campagne de prédication de 1230-31, voir supra, p. 16. Notre approche des Postilles est évidemment quelque peu simpliste car une grande part des commentaires compile des œuvres antérieures.

${ }^{93}$ In Psalm. 67(68).31 : "In sagina vaccarum : id est in pinguedine prebendarum », éd. Cologne, 1621, t. II, f. 170v. 
loin, lexégète attaque la pratique de donner des bénéfices en curie par népotisme ${ }^{94}$. Dans la Postille sur les Évangiles, il est aussi traité de laccumulation des bénéfices ${ }^{95}$. Mais c'est dans les commentaires sur les Épîtres pauliniennes et sur l'Apocalypse que lon trouve des échos plus certains de la querelle sur la pluralité des bénéfices : des arguments issus de sermons ou destinés à alimenter une prédication universitaire attaquant les pluralistes. Commentant le passage de la première épître aux Corinthiens où Paul recommande aux chrétiens d'imiter la discipline de lathlète qui concourt pour la couronne, le commentateur lance une pique aux clercs chargés de plusieurs prébendes et qui, lourds, ne peuvent courir en athlètes de la prédication ${ }^{96}$. Un peu plus loin, dans l'Épître aux Galates, le commentateur discute et réfute largument des pluralistes selon lequel les dispenses de cumul sont comparables aux autorisations de polygamie accordées par Dieu aux patriarches ${ }^{97}$. Il s'agit d'un point qui est débattu dans les questions disputées et le commentaire a pu être influencé par celles-ci. Mais c'est certainement, dans la Postille morale sur l'Apocalypse Aser cum pinguis, texte qui date vraisemblablement des années 1235 , que l'on trouve les attaques les plus virulentes. L'exégète y reprend une métaphore développée par Guillaume d'Auvergne qui compare les pluralistes à des ânes ${ }^{98}$. Nous sommes ici à la limite de linjure.

Mais tandis que le dominicain responsable du commentaire d'Aser cum pinguis couchait sur le parchemin ses attaques virulentes, d'autres frères prêcheurs étaient beaucoup plus indifférents aux mœurs de l'élite du clergé séculier. Guerric de Saint-Quentin dans son quodlibet, postérieur d'une dizaine d'années, dévoile des vues modérées ${ }^{99}$. Si l'on quitte le couvent SaintJacques pour se rendre à celui d'Orléans, lenseignement des jeunes frères n'accorde aucune importance au pluralisme. C'est ce qui ressort en tout cas de la Summa de casibus de Guillaume de Rennes, lecteur au couvent d'Orléans et auteur aussi d'une glose très influente à la Summa

${ }^{94}$ In Ps. 87.16 : «Pauper sum ego et in laboribus a iuventute mea : [...] Istum versum non possunt dicere nepotes et consanguinei pontificum et cardinalium Pauper sum etc. sed e contrario 'dives sum et sine laboribus a iuventute mea'. Prebende enim dantur in curis; neque ipsi sunt in labore, nec corporis nec anime ", éd. citée, f. $229 \mathrm{v}$.

${ }^{95}$ Nous nous appuyons sur B. Smalley, The Gospels in the Schools c. $1100-c .1280$, Londres, 1985, p. 143 qui mentionne In Lucam 9.38 : "Quia unicus est mihi: Contra illos qui habent plures ecclesias. Quot enim habent ecclesias, tot habent populos et tot filios infirmos. Qui ergo unum curare non sufficit, quomodo curabit plures ", éd. citée, t. VI, f. 188v et In Ioannem 2.15-16 (Jésus nettoie le Temple) où le commentateur attaque les clercs de cours et les avocats qui fuient les écoles et accumulent les prébendes (Ibid., f. 192r).

${ }^{96}$ In 1 Corint. 9.24 : " Hic ostendit per similitudinem sumptam a currentibus in stadio propter coronam vel aliquid etiam huiusmodi. Isti etiam vestimenta que non sunt necessaria deponunt ne impediantur a cursu q. d. apostolus, ergo ex quo isti abstinent a licitis et ergo multo magis volui abstinere a sumptibus quos licite possem accipere ut non impediretur cursus predicationis mee. Cum ergo due prebende valde minus sint licite quam expense diei, predicatores nostri non debent eas accipere quod si faciant non mirum si predicationis eorum impediatur ", éd. citée, t. VII, f. 96v.

${ }^{97}$ In Galat. 5 : «Item multiplicatio uxorum fuit legale, vel ad minus cum lege erat, ergo si habes simul prebendas plures vel ecclesias : Christus nihil tibi proderit. Propterea Deuter. 17.[17] dicitur de rege : Non habebit plurimas uxores que alliciant animam eius, ergo quia nobilis es, ideo plures non potes habere. Sed dices non alliciunt animam meam. Utinam et tamen si verum est, quod dicis, adverte quod legale est hoc. Sed dices. Literatus sum, plures non alliciunt me. Vide Salomonem, qui cum sapiens fuerit 3 Reg. 11.[1] adamavit uxores alienigenas multas. Et postea sequitur quod fecerunt eum adorare idola. Sic patres nostri theologi multiplicibus redditibus adorant idola avaritie », éd. citée, t. VII, f. 163r.

${ }^{98}$ Voir, infra, p. 45.

${ }^{99}$ M.-M. DufeIL, Guillaume de Saint-Amour et la polémique universitaire parisienne (1250-1259), Paris, 1972, p. 37678. 
de casibus de Raymond de Peñafort. La Summa de casibus de Guillaume de Rennes rassemble selon l'ordre des décrétales des questions de quolibet ; un exercice de l'éducation dominicaine inspirée des questions disputées universitaires ${ }^{100}$. Le chapitre sur les prébendes est extrêmement court à côté de ceux fleuves sur la confession et lexcommunication. La question sur le pluralisme rassemble quelques notes mnémotechniques. Guillaume pose néanmoins comme hypothèse que l'évêque a gagné un droit coutumier de dispenser du cumul des bénéfices sans charge d'âmes ${ }^{101}$. Un argument qui le situe plutôt dans le camp des partisans du pluralisme; en tout cas, il s'écarte des positions de son provincial.

Avant la grande crise de la querelle entre mendiants et séculiers, les dominicains n'ont pas de position commune sur les questions de morale ecclésiastique. Ils sont partagés par les mêmes courants que ceux qui traversent l'Université.

\section{La question disputée (A) D’Hugues de Saint-Cher de I235-I236 $6^{102}$}

Un couvent Saint-Jacques hésitant entre enragés et réalistes, un évêque de Paris à la politique trop transparente; le beau récit moral de Thomas de Cantimpré semble tomber en pièces. Il ne faut pas néanmoins le ranger au rayon des pieux mensonges, lanecdote sur Philippe le Chancelier.

Dans la question disputée par Hugues de Saint-Cher en 1235-36, on trouve un argument qui était déjà évoqué lors de la campagne de sermons de 1230-31 : les positions pour ou contre le pluralisme ne sont que des opinions, on ne peut leur donner une valeur de norme scientifique en les prédiquant en vérité. L'ad obiecta est particulièrement intéressant :

Mais qu'il soit licite de posséder plusieurs prébendes ou plusieurs églises, sinon dans les cas qui sont des exceptions, c'est une opinion qui n’a jamais eu cours. Au

\footnotetext{
${ }^{100}$ A. Duval, "L'étude dans la législation religieuse de saint Dominique », dans Mélanges offerts à M.-D. Chenu, Paris, 1967, p. 221-247; L. Boyle, "Notes on the Education of the Fratres communes in the Dominican Order in the Thirteenth Century ", dans Xenia Medii Aevii historiam illustrantia oblata Thomas Kaeppeli, o. p., Rome, 1978, p. 249-67 (repris dans ID., Pastoral Care, Clerical Education and Canon Law, Londres, 1981).

${ }^{101}$ Guillaume de Rennes, Summa de casibus, De prebendis : " Queritur an habere plures prebendas vel plura beneficia sit peccatum mortale? Respondeo quod sit, nisi in casibus exceptis per illum versiculum : defectus, pendens, paupertas, gratia, servans. De gratia, id est de dispensatione dico quod in prebendis sine cura animarum sufficit hodie de consuetudine quam papa scit et non reprobat. Dispensatio episcopi qui eo ipso enim videtur dispensare quod dat scienter prebendam habenti aliam etiam alia ecclesia nisi aliud appareat. Consideranda tamen est causa dispensationis sicut et in aliis dispensacionibus, alias etiam si excusentur quo ad Ecclesiam militantem quo ad Dominum tamen non ", ms. Paris, BnF, lat. 3723, f. 35v-36r. Largument qu'une dispense obtenue sans juste cause juste est valide juridiquement mais reste un péché se retrouve dans les déterminations d'Hugues de Saint-Cher (F. Stegmüller, « Die neugefundene Pariser Benefizien-Disputation des Kardinals Hugo von St. Cher OP », Historisches Jahrbuch, 72 (1953), p. 176-204, ici p. 197) avec la même opposition entre l'Église militante et l'Église éternelle. Dans sa glose à RAYMOND DE PeÑAfOrt, Summa de casibus, 13 (éd. Lyon, 1718, p. 263), Guillaume développe le même argument et fait une allusion à lautorité de saint Bernard sur la dispense. Là, encore c'est un argument qui est utilisé par Hugues de Saint-Cher dans la première version de sa question disputée (cf., infra, p. 27, n. 113). On peut conclure que Guillaume de Rennes a connu la première version de la question disputée d'Hugues, ce qui place sa propre œuvre dans les années postérieures à 1236 .

${ }^{102}$ Selon notre reconstitution (cf. infra, Annexe : «Le dossier des textes »), il existe trois états de la question disputée par Hugues : la version $A$ date de 1235-36, $B$ peut-être des années 1237 ; $C$ est une réélaboration postérieure. $C$ est édité par Stegmüller (cf. la note précédente); $A$ et $B$ sont inédits.
} 
contraire, tous les jurisconsultes et les théologiens disent que cela ne peut avoir lieu et même, la raison le dicte et l'écriture des saints le confirme. De plus, à ce que j'ai entendu, certains pluralistes très savants dans les trois droits divin, civil et canonique en ont porté témoignage ${ }^{103}$. En effet, alors qu'ils étaient à larticle de la mort, ils ont librement résigné leurs bénéfices. Un certain clerc éminent, parmi les plus éminents de toute la France, disputa pendant bien une année avec moi sur ce sujet, et il disait qu'il était licite de posséder plusieurs prébendes. Et moi, je lui disais que le jour où il craindrait pour ses jours, il changerait d'opinion. Et le Seigneur voulut éprouver s'il disait vrai. Et la même année, il laccabla d'une maladie relativement grave, et lui apeuré, alors que j'étais présent, résigna tous ses bénéfices sinon un. Et pour ceci, j’ai rendu grâce à Dieu qui a manifesté la vérité. J'ai entendu la même chose de plusieurs maîtres importants qui avant de mourir ont résigné tous leurs bénéfices sauf un. Et pourquoi ont-ils fait cela sinon par ce que la conscience et la raison intérieure leur enseignent et leur dictent que ce n'est pas licite d'en avoir plusieurs; même si l'ambition suggère à certains que c'est permis; mais ce que propose lambition ce n'est pas une opinion mais plutôt une illusion ${ }^{104}$.

Qui se cache derrière ce "clerc éminent, parmi les plus éminents de France "? Il faut très certainement reconnaître Philippe le Chancelier. Le passage est aussi précieux car il montre la cristallisation de lanecdote du maitre pluraliste qui se repent à larticle de la mort. On en trouvait déjà les linéaments chez Robert de Courson. Mais, elle trouve ici, alimentée de lexpérience personnelle d'Hugues, une forme définitive. Hugues révèle aussi avec gaucherie mais clarté son but. Il veut faire concorder théologie et droit dans la critique du pluralisme contrairement à Guillaume d'Auvergne qui, comme Robert Grosseteste, ne marquait que mépris pour les jurisconsultes ${ }^{105}$. Il y a chez Hugues une volonté d'encyclopédisme qui est caractéristique de la première génération dominicaine et qui tranche avec d'autres tendances qui veulent constituer la théologie en une science spéculative parfaitement autonome.

\footnotetext{
${ }^{103}$ Littéralement, la phrase latine implique qu'Hugues entend le témoignage des maîtres pluralistes. Mais, il nous semble que si on corrige la concordance des temps, le passage fait plus sens.

104 « Ad 8 Ad id quod vir obiicitur de non predicanda opinione contrarius quod nunquam est predicanda opinio id est in predicatione asserenda. Sed quod licitum sit habere plures prebendas vel plures ecclesias, nisi in casibus exceptis, nunquam fuit opinio ; immo omnes iurisperiti et theologi dicunt quod non licet; hoc etiam ratio ipsa dictat et scriptura sanctorum confirmat. Etiam illi qui habent plures hoc testati sunt, me audiente, periti valde in triplici iure divino, civili et canonico. Et hoc patet, quia omnes in periculo mortis libenter resignant eas. Quidam magnus clericus, de maioribus totius Francie, per totum unum annum fere mecum disputaverat super hoc, et dicebat quod licitum erat habere plures. Et cum ego dicerem ei quod, si esset in periculo mortis, mutaret opinionem suam, dicebat quod nullo modo mutaret opinionem suam de hoc. Et Dominus voluit probare utrum verum diceret. Et in eodem anno dedit ei infirmitatem satis gravem, et timuit sibi; et me presente, omnes resignavit preter unam et eo gratias reddidi Deo qui manifestavit (ms. manifestarat) veritatem. Hoc idem audivi de pluribus magnis magistris, qui in fine omnes resignabant, ad minus preter unam. Et quare faciunt hoc, nisi quia conscientia et ratio interior docet et dictat quod non est licitum habere plures, licet ambicio dicat aliquibus quod licet sed quod ponit ambitio non est opinio sed magis deceptio. [...] Igitur assere quod non licet habere plures prebendas non est predicare opinionem sed asserere veritatem ", ms. Douai, Bibl. mun., 434, t. II, f. 125v).

${ }^{105}$ Voir, infra, p. 45.
} 
Les listes de pro et de contra de la question disputée de 1235-36 marquent ainsi un effort de renouvellement des sources. On n'y trouve aucune utilisation directe des questions voisines du Scriptum sur la simonie. La compilation théologique, première œuvre d'Hugues, n'a semblé d'aucune utilité. Le maître a voulu partir sur des bases neuves. Dans le dossier préparé par lopponens et le respondens, il y a certainement des arguments repris des disputes contemporaines. D'autres proviennent vraisemblablement de Robert de Courson qui a dû être relu à Pépoque et mis en fiches ${ }^{106}$. Le titre sur les prébendes du récent Liber Extra de 1234 est utilisé; le Décret est cité plusieurs fois. Hugues utilise même les Compilationes Antique. En effet, il cite longuement une décrétale dans sa version transmise par la Compilatio Secunda de Jean de Galles. En effet, dans ce texte, Alexandre III écrit à larchevêque de Gênes pour l'enjoindre de se garder d'introduire dans son diocèse la coutume de l'église gallicane en matière du pluralisme ${ }^{107}$. Ce passage a été coupé par Raymond de Peñafort dans le Liber Extra alors qu'il constituait un précieux argument pour montrer que les papes n'ont pas tacitement approuvé la coutume française de cumuler les bénéfices.

La question utilise aussi la doctrine canonique bolonaise des années 1210-1220. Explicitement, Hugues reprend une glose au Décret de Gratien, dont nous n'avons malheureusement pas réussi à trouver la source. À un autre endroit, le maître dominicain propose un raisonnement qui semble décalquer la doctrine du canoniste bolonais Damase et qui provient sans doute d'une glose aux Compilationes Antique ${ }^{108}$. Cette utilisation de la doctrine canonique bolonaise est ponctuelle, partielle et partiale; elle n'en est pas moins significative. Avant la diffusion des gloses ordinaires sur le Décret de Gratien et le Liber Extra, les livres de droit bolonais devaient être rares à Paris. Y chercher des autorités montre que le maître dominicain souhaitait accorder jurisconsultes et théologiens ${ }^{109}$.

La détermination constitue le cœur de la question. Larticulation de celle-ci avec les pro, contra et ad obiecta est faible. Hugues développe une position qu'il n'a pas vraiment discutée auparavant. Celle-ci comporte trois éléments. Il est d'abord énuméré les situations dans lesquelles le cumul est permis, puis il est indiqué qui a le droit de dispenser dans les autres cas et enfin, dans un passage plus moral, il est expliqué que même si une dispense peut-être licite sur le plan du droit et de linstitution, le cumul n'en reste pas moins un péché si la cause de la dispense n'est pas juste ${ }^{110}$. Dans la détermination du premier état de la question $(A)$, le cumul est autorisé dans cinq cas : par nécessité ou manque de clercs; lorsque le revenu du bénéfice est trop faible; s'il y a utilité commune de l'Église ; si un bénéfice est une annexe à un autre et si un bénéfice est en commende d'un autre ${ }^{111}$. Dans les autres situations, il faut une dispense

\footnotetext{
${ }^{106}$ Par exemple le neuvième argument pro : «Item Dominus pape scit hoc quod multi habent plura beneficia nec reprobat sed confirmat. Ergo non est malum », ibid., f. 124v, cf. supra, p. 8.

${ }^{107} 2^{\mathrm{a}}$ Comp. 3.4.1 $=$ X 3.5.15.

${ }^{108}$ Cf. infra, p. 39.

${ }^{109}$ Cf., le texte cité supra, p. 26, n. 104.

${ }^{110}$ Quelques années plus tard, Innocent IV tentera de prouver qu'en matière bénéficiale, le pape peut dispenser sine causa, cf. L. Buisson, Potestas und Caritas. Die päpstliche Gewalt in Spätmittelalter, Cologne / Vienne, $1982^{2}$, p. 97.

111 « Solutio .v. sunt casus in quibus licitum est habere plura beneficia ecclesiastica. Primus est propter necessitatem sive cantitatem personarum; secundus propter utilitatem communem; tertius propter insufficienciam reddituum ; quartus propter dependenciam quando unus dependet ab alio ; quintus propter commendationem id est quando alterum est commendatum alteri intitulati. In hiis .v. casibus licitum est habere plura
} 
pontificale. Mais, Hugues ajoute, reprenant un bon mot de saint Bernard, que pour qu'il s'agisse d'une dispensatio et pas d'une dissipatio, il faut que la dispense soit donnée lorsqu'il y a nécessité ou utilité commune de l'Église. Hugues synthétise une source canonique - qui est, là encore, vraisemblablement inspirée de l'enseignement de Damase $\mathrm{e}^{112}$ — et une autorité patristique mais le résultat est vraiment maladroit : la fin de la détermination - le pape doit dispenser en cas de nécessité ou d'utilité — contredit le début — s'il y a nécessité ou utilité, nul besoin de dispense - .

\section{L'évolution de la position d'Hugues de SAint-Cher}

Les versions postérieures $B$ et $C$ de la question disputée ne modifient pas substantiellement les positions du maitre dominicain mais elles montrent des évolutions significatives.

Le dossier des autorités et des sources change peu, même si de nombreux pro et contra sont recomposés. On ne trouve pas de nouvelles sources juridiques explicites. Les arguments qui provenaient de la Somme de Robert de Courson tendent à disparaître. Au contraire, les sources bibliques et les raisonnements exégétiques croissent. De manière symptomatique, la détermination des questions $B$ et $C$ débute par une comparaison entre pluralisme et polygamie des patriarches alors que $A$ commençait par la règle juridique. Il y a une application pour rendre la démonstration plus théologique et exégétique.

Le statut normatif de la question disputée devient aussi beaucoup plus mesuré. Un des ad obiecta de $A$ expliquait que penser que le pluralisme était illicite n'était pas une opinion mais une vérité que lon pouvait prédiquer. Cette idée disparait des versions ultérieures. Au contraire, Hugues introduit sa détermination par la formule prudente : sine preiudicio melioris sententie $^{113}$. Le pape est aussi traité avec beaucoup plus de respect. La référence à saint Bernard désobligeante pour le pontife a été supprimée. Hugues note dans un ad obiecta que «le droit ecclésiastique est entre les mains du seigneur pape ${ }^{114}$.» La recomposition de la détermination

beneficia aliter non nisi ex dispensatione domini Pape que debet esse sicut dicit beatus $\mathrm{G}<\mathrm{regorius}>$ ad Augustinum 'semper vel propter necessitatem vel propter communem utilitatem, aliter enim non est dispensatio sed dissipatio' et ita supponitur quod papa semper dispensat propter alterum istorum et quicumque querint ab eo dispensationem nisi habeat secundum conscientiam suam alterum istorum ego credo quod ipse decipit se », ms. cité, f. 125r. La citation de Grégoire citée de tête par Hugues est fausse, il s'agit en fait d'un passage célèbre du De consideratione de saint Bernard, Bernard de Clairvaux, Opera Omnia, éd. J. Leclerce et H. M. Rochais, Rome, 1963, t. III, p. 445.

${ }^{112}$ Damase, ad $2^{a}$ Comp. 3.3.2, $\mathrm{v}^{\circ}$ 'ecclesiastica' : « regulare est quod unus plures ecclesias vel beneficias habere non debeat ut hic. Fallit autem in casibus quia potest quis habere plures ex dispensatione episcopi puta si sint due insufficientes duobus prelatis dabuntur uni ut Lxx di., Sanctorum (D. 70 c. 2) propter raritatem clericorum xxI q. I, Relatio (C. 21 q. 1 c. 5). Item si unam habeat intitulatam et aliam commenditam xxI q. I, Qui plures (C. 21 q. 1 c. 3). Quidam dixerunt quod preter unam habere intitulatam aliam ut beneficium hoc reprobatur per istam decr. [...] D<amasus> ", ms. PARIS, BnF, lat. 3930, f. 83r. Raymond de Peñafort propose aussi dans sa Summa de casibus (op. cit.) cinq cas dans lesquels le cumul est possible mais la liste n'est pas exactement la même que celle que donne Hugues. Geoffroy de Bléneau dans sa très courte question disputée sur la pluralité des bénéfices reprend dans sa détermination ces cinq cas (STEGMüller, op. cit., p. 203).

${ }^{113}$ STEGMüLLER, op. cit., p. 195.

${ }^{114}$ L'ad obiecta est intéressant et mérite d'être cité en entier : "Ius autem ecclesiasticum comissum est domino pape, et ideo, ubi videt recompensationem, potest ipse dispensare cum aliquo, ut habeat plura beneficia. Sed mentiri et similia huiusmodi, que pure spectant ad ius divinum, nec sunt commissa domino pape, nullo modo recipiunt dispensationem; et ideo papa non potest cum talibus dispensare, ut eis liceat mentiri vel 
affirme plus clairement la place centrale du Saint-Siège dans Porganisation du pluralisme. Hugues explique que le pluralisme est interdit sinon dispense. Il peut s'agir d'une dispense de droit si le revenu est insuffisant ou une dispense selon une décision judiciaire s'il y a nécessité ou utilité commune. Seul le pape a le droit d'accorder ce second type de dispense. S'il s'agit d'un bénéfice annexé ou en commende, on ne peut vraiment parler de plusieurs bénéfices mais d'un bénéfice avec plusieurs revenus. Dans Pultime version de la détermination, celle de $C$, Hugues déplace le curseur en l'écartant légèrement des thèses pro-pontificales. Il ajoute, en effet, que la dispense de droit doit être accordée par l'évêque et que la dispense selon une décision judiciaire peut-être déléguée par le pape à une tierce personne ${ }^{115}$.

Les trois solutions proposées par Hugues sont grosso modo les mêmes mais les déterminations de $B$ et de $C$ sont beaucoup plus limpides que celles de $A$. Quels sont les facteurs de cette clarification juridique? Henri de Suse a enseigné le droit canon dans les années 1230 à Paris. La Summa Aurea est écrite sur une longue durée et achevée vers 1253 et il ne semble pas que l'on y trouve d'allusions à la querelle des bénéfices de 1236-38. Hostiensis connaissaitil Hugues de Saint-Cher à l'époque? Le juriste cite dans sa Somme des opinions d'Hugues de Saint-Cher sur des points de théologie ${ }^{116}$. Hostiensis suivait-il des cours de théologie lors de séjour parisien et en particulier celui d'Hugues de Saint-Cher. Les citations d'Hugues de Saint-Cher dans la Summa Aurea pourraient aussi renvoyer à des discussions à Lyon durant le concile ou à des conversations alors qu'ils cheminaient ensemble lors de la légation d'Hugues en Allemagne en 1251-53 entre les deux hommes. La position d'Hostiensis sur la pluralité des bénéfices est différente de celle d'Hugues de Saint-Cher. Henri de Suse est bien moins tranché et accorde plus de pouvoirs de dispense à l'évêque ${ }^{117}$. Mais, les œuvres d'Hostiensis sont tardives et ne reflètent pas nécessairement ce qu'il enseignait dans les années 1230. C'est une hypothèse séduisante de voir la patte d'Hostiensis dans les questions disputées d'Hugues mais, pour linstant, il n'y en a aucune preuve.

Les états successifs de la question montrent en tout cas qu'Hugues s'est écarté des idées à contre-courant de Guillaume d'Auvergne. Il colle à l'opinion majoritaire de la doctrine canonique des années 1240 : le pluralisme est interdit en général et seul le pape a le droit d'accorder des dispenses. Cette place qu'il accorde au pontife n'est pas celle de tous les dominicains à cette époque. Guillaume de Rennes dans sa glose à la Summa de casibus de Raymond de Peñafort défend contre la position du texte qu'il commente, que les évêques peuvent dispenser les

verba otiosa dicere, licet in talibus minus peccet homo nisi in casu ", ibid., p. 200. Il faut remarquer qu'Hostiensis qui appliquera au pouvoir pontifical de dispense le concept de potestas absoluta forgé en théologie par Hugues de Saint-Cher développe la même idée : le pape ne peut dispenser du droit naturel : A. Boureau, «Le vœu monastique et l'émergence de la notion de puissance absolue du pape (vers 1270), Cahiers du Centre de Recherches Historiques, 21 (1998), p. 23-34 (ici p. 31).

${ }^{115}$ STEGMÜLleR, op. cit., p. 196.

${ }^{116}$ Hostiensis, Summa Aurea, lib. 1, De summa Trinitate, $\mathbb{} 11$ (Bâle, 1573, col. 11); De fide catholica, $\mathbb{} 4$ (Ibid., col. 15) ; J.-F. Schulte, Die Geschichte der Quellen und Literatur des canonischen Rechts, Stuttgart, 1875 (repr. Graz, 1956), t. 2, p. 127, n. 24 indique, sans donner de références, qu'Hostiensis cite aussi un Guil. Paris., vraisemblablement Guillaume d'Auvergne. [Hostiensis cite aussi une opinion d'Hugues sur le dîmes prédiales : lib. 3 ; De decimis et primitiis, $\mathbb{S} 15]$.

${ }^{117}$ Voir par exemple lib. 3, De institutionibus, $\mathbb{} 4$ (Ibid., col. 706-707). Le débat sur la pluralité des bénéfices est complexe et dispersé dans la Summa, voir par exemple lib. 3, De praebendis et dignitatibus, $\$ 6$ (Ibid. col. 700) où Hostiensis se met lui même en scène comme pluraliste. 
clercs pluralistes ${ }^{118}$. Néanmoins, les choix d'Hugues et de Raymond en matière de dispense marquent la cristallisation de lidentité mendiante. Dans la théologie morale parisienne du premier quart du xıII ${ }^{\mathrm{e}}$ siècle, le pape est présent mais en pointillé. Il est un arbitre lointain qui constitue un dernier recours. Les affaires doivent se régler sur place. Les mendiants, de par leur apostolat et leur organisation institutionnelle, ont été beaucoup plus sensibles au pouvoir direct du sommet et à Pinfinie souplesse de la dispense pour s'extirper des règles locales.

\section{ÉPILOGUE : LE CONCILE DE LONDRES DE I237}

En 1237, alors que Paris bruit des questions sur la pluralité, Otton de Tonengo, légat pontifical, traverse la Manche pour se rendre en Angleterre avec dans ses bagages un brillant sujet, Henri de Suse ${ }^{119}$. Débarqué sur les côtes anglaises, Otton organise la tenue d'un vaste concile à Londres où il édictera des canons réformateurs. Le clergé anglais se rassemble avec réticence. Il a transpiré que le légat veut réglementer sur la pluralité des bénéfices et les bruits courent que, pour cette raison, des clercs se préparent à lassassiner. Otton prend ces menaces très au sérieux et il obtient d'Édouard III que trois nobles de l'entourage royal lui servent de gardes du corps durant son séjour londonien. C'est dans une atmosphère alourdie par la crainte des sicaires pluralistes que s'ouvre le concile. Comme dans tout bon concile anglais, le premier jour est entièrement rempli par les disputes protocolaires entre larchevêque de York et celui de Cantorbéry, Edmond Rich. On rentre dans le vif du sujet le deuxième jour et le légat fait lire les statuts qu'il compte promulguer. Après avoir entendu le canon qui condamne le pluralisme, l'évêque de Winchester, Gautier de Cantiloupe, s'avance au centre de l'assemblée, enlève sa mitre - vraisemblablement pour indiquer qu'il parle à titre privé et non comme évêque - et s'adresse au légat :

Père saint, de nombreux nobles de notre sang ont obtenu plusieurs bénéfices et n'ont pas encore obtenu de dispense. Certains d'entre eux sont d'un âge avancé et ont jusqu'à présent vécu honorablement accomplissant leurs obligations d'hospitalité en ouvrant leurs portes autant qu'ils pouvaient pour distribuer des aumônes. Il serait excessivement dur de les priver de leurs bénéfices et de les jeter dans une ignominieuse pauvreté. Si je fais confiance à mon expérience personnelle, certains jeunes gens, têtes brûlées, seront conduits aux pires extrémités avant qu'ils n'abandonnent leurs bénéfices, sauf un seul. En effet, avant d'être appelé à cette dignité, je m'étais persuadé que si je perdais un seul bénéfice à cause de cette constitution (De multa), je les perdrais tous. Comme de nombreux autres sont dans le même cas, nous supplions votre sainte paternité, eu égard à votre salut et au nôtre, de consulter le seigneur pape sur un statut de ce type ${ }^{120}$.

\footnotetext{
${ }^{118}$ Voir, supra, p. 25, n. 100.

${ }^{119}$ Sur la légation d'Otton, voir D. M. Williamson, «Some aspects of the legation of Cardinal Otto in England, 1237-41 », English Historical Review, 64 (1949), p. 12-30.

${ }^{120}$ Matthieu Paris, Chronica : " Pater sancte, cum multi nobiles quorum sanguis noster est plura optineant beneficia, cum quibus nondum dispensatum est, quorum etiam aliqui provecte sunt etatis et usque ad presens honorifice vixerunt et hospitalitatem ad posse procurando elemosinas patentibus ianuis erogarunt, durum es-
} 
Le cri du cœur de Gautier reprend un thème classique de la rhétorique médiévale de la norme depuis Yves de Chartres. Il faut temporairement se dispenser d'appliquer une loi, si sa mise en pratique provoque plus de mal que de bien; la rigor iuris doit être tempérée d'humanité. Le plaidoyer de l'évêque de Winchester ne fut certainement pas sans effet. Les statuts promulgués par Otton abordent le pluralisme avec agacement mais aussi avec une certaine retenue. Le légat explique qu'il ne promulgue pas à ce sujet de statut mais se borne à donner des conseils. Du reste, ajoute Otton, les canons de Latran IV sont suffisamment clairs; il suffit de les appliquer. Il ne fait, malgré tout, pas de doute que le cumul de dignités, de personnats ou de bénéfices avec charges d'âmes est très périlleux ${ }^{121}$. Otton en reste à cette exposition du pluralisme comme péché qu'il partage avec Hugues de Saint-Cher. Il n'est pas improbable qu'Otton ait assisté ou ait eu vent des disputes parisiennes. Le légat n'oblige donc pas explicitement les évêques à faire la chasse aux clercs rebelles, ni n'organise une procédure pour permettre aux récalcitrants de se mettre en règle. Sa législation est, sur ce point, un coup d'épée dans l'eau. Du reste, Gautier de Cantiloupe dans ses statuts synodaux de quelques années postérieurs se gardera bien de publier le canon sur le pluralisme ${ }^{122}$.

Le psychodrame du concile de Londres montre bien que tout au long des années 1230, alors que se forge une opinion publique sur le cumul des bénéfices, les liens entre les discussions scolastiques des maîtres, la législation ecclésiastique et la politique locale sont incessants. Certes, les termes de ce débat sont codés. Personne, même Gautier de Cantiloupe, n'est pour un pluralisme généralisé. Peu de gens imaginent qu'il devrait être totalement interdit. L'enjeu réside dans les limites de la tolérance et dans le contrôle de la dispense. Le parcours intellectuel d'Hugues révèle une évolution sans nul doute typique pour sa génération. Le problème n'en est pas un avant son apparition dans la campagne de prédication de la grève universitaire de 1230-31. Comme certains maîtres, il a dû croire à l'époque que lon pourrait décapiter le monstre du cumul grâce à quelques sermons bien sentis et une batterie d'arguments logiques. Néanmoins, au fur et à mesure que la recherche des sources et des autorités progressait, il a dû prendre la mesure de la complexité du problème. Sa solution finale est mitigée afin de mieux coller à lopinion majoritaire du moment et aux positions pontificales.

On aimerait connaître sa politique en matière de dispense après son élévation au cardinalat. Malheureusement, il ne semble pas qu'il existe de sources qui permettent de lapprécier. La question du pluralisme ne s'est en tout cas nullement éteinte dans les années 1240; elle va rebondir tout au long du XIII ${ }^{\mathrm{e}}$ siècle. Mais, c'est moins l'issue du problème que son mode d'existence qu'il faut retenir. Le pluralisme naît comme un débat. Certes, les règles de celui-ci sont bien différentes de ce que lon pourrait trouver actuellement. Le débat médiéval se nourrit de joutes oratoires, de sermons bien troussés, d'écrits universitaires farcis de références et

set nimis tales, suis beneficiis spoliatos, in ignominiosam trudi paupertatem. Quidam vero iuvenes feroces ac strenui maximis periculis se opponerent antequam suis se sinerent privari beneficiis, unico tantum retento; quod bene perpendo per memetipsum. Antequam enim ad istam vocarer dignitatem, proposui in animo meo quod si unicum amitterem beneficium talis pretextu constitutionis, omnia amitterem; unde timendum est quod multi ad presens in simili proposito perseverent. Quoniam igitur multitudo talium in causa est, sancte paternitati vestre supplicamus quatinus ob salutem vestram et nostram super huiusmodi statuto dominum papam consulatis ", éd. F.M. Powicke, C.R. Cheney, Councils and Synods with other Documents relating to the English Church, Oxford, 1964, t. II, p. 243.

${ }^{121}$ Can. 13 (Ibid., p. 251).

${ }^{122}$ Ibid., p. 294 et sqq. 
de ces exercices de persuasion par la loi que sont les conciles. Il s'exprime à travers d'absconses citations bibliques et des arguties juridiques. Il n'en a pas moins des enjeux véridiques et tangibles. De même, que si aujourd'hui l'État français décidait d'appliquer strictement la règle d'obligation de résidence des universitaires, ceci ne créerait qu'une vaguelette sur le vaste et profond océan du droit administratif mais aurait des conséquences dramatiques tant sur la vie familiale de certains que sur lorganisation de la recherche. Au Moyen Âge, en tout cas, les universitaires avaient lespoir d'écrire la norme qui les régissait. 


\section{Annexe : Hugues de SAint-Cher ÉtAit-IL un Juriste ?}

Les notices biographiques actuelles mentionnent qu'Hugues fut docteur en droit canonique avant de rentrer dans lordre des prêcheurs ${ }^{123}$. Aucune source médiévale, pourtant, ne donne ce titre académique à Hugues. Ce sont les historiographes dominicains Quétif et Échard qui exprimèrent les premiers cette idée et ils furent ensuite recopiés par tous ${ }^{124}$. Cette affirmation peut pourtant être reconsidérée à la lumière tant des données biographiques que du témoignage des œuvres théologiques d'Hugues.

\section{Hugues de Saint-Cher juriste d’après les données biographiQues}

Quétif et Échard pensaient avoir découvert la preuve du doctorat en droit canonique d'Hugues dans un passage des Vite Fratrum qui raconte la conversion d'Humbert de Romans vers $1224^{125}$. Le récit dit qu'Humbert après avoir enseigné en tant que maître ès arts, suivait des cours de droit canonique et, en cachette le matin, allait aux écoles théologiques. Après s'être décidé à devenir dominicain, il va voir son maître (magister suus) Hugues de Saint-Cher qui, selon Gérard Frachet, était déjà bachelier en théologie, et s'ouvre de son projet. Hugues l'encourage et lui dit qu'il veut aussi rentrer dans l'ordre mais qu'Humbert sait bien qu'il doit d'abord expédier certaines affaires (quedam negocia) pour son maitre Guillaume de Savoie. De ce passage, Quétif et Échard ont déduit qu'Hugues était le maitre en droit canonique d'Humbert.

Guillaume de Savoie est l'un des fils du comte de Savoie. À l'époque, il a un peu plus de vingt ans. Son père a déjà obtenu pour lui par l'entregent d'Édouard III des bénéfices en Angleterre ${ }^{126}$. Dans les années 1224, il devient doyen du chapitre Saint-Maurice de Vienne et évêque-élu de Valence. Selon la technique de la Maison de Savoie, il ne prend pas les ordres majeurs et reste dans la position d'évêque-élu ${ }^{127}$. Il est ainsi dans un document nommé selon le curieux titre d'administrateur. Guillaume sera du reste un évêque apprécié pour sa vigueur guerrière et sa détermination à défendre les biens temporels de l'évêché128. En 1238, il est élu sur le siège de Liège. Il meurt en 1240. Hugues a certainement des liens avec les fils Savoie ${ }^{129}$. Ainsi en 1244, avant sa création comme cardinal, Innocent IV le charge de livrer le pallium à Boniface, frère de Guillaume, élu à larchevêché de Cantorbéry ${ }^{130}$.

Quels sont les negocia dont s'occupait Hugues de Saint-Cher pour Guillaume vers 1224. Il pourrait s'agir de négociations dans la politique ecclésiastique de Valence et Vienne en vue d'obtenir l'évêché pour Guillaume. C'est possible, mais Paris n'est pas le bon lieu pour cela. On pourrait penser à une mission à la cour capétienne. C'est aussi peu probable car

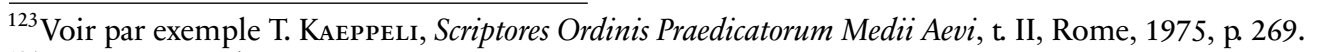

${ }^{124}$ J. QuétIF et J. Échard, Scriptores Ordinis Praedicatorum, t. I, Paris, 1719, p. 195.

${ }^{125}$ Gérard de Frachet, Vitae Fratrum Ordinis Predicatorum necnon Chronica ordinis, éd. B.-M. Reichert, Louvain, 1896 (Monumenta Ordinis Praedicatorum Historica 1), p. 170-171

${ }^{126}$ E. L. Cox, op. cit., p. 15.

${ }^{127}$ Philippe, frère de Guillaume, usera de la même astuce lorsqu'il deviendra en 1245 archevêque de Lyon, cf. supra p. 2.

${ }^{128}$ Cox, op. cit., p. 34 et sqq. Voir aussi les prouesses militaires de Guillaume lors du siège de Brescia (ibid., p. 67-68).

${ }^{129}$ Néanmoins, lexamen de D. Carutti, Regesta Comitum Sabaudiae, Turin, 1889 ne nous a pas permis de découvrir de traces d'Hugues dans l'entourage de la maison de Savoie avant 1244.

${ }^{130}$ Les registres d'Innocent IV, éd. É. BerGER, Paris, 1884-1911, $\mathrm{n}^{\circ} 585$.
} 
à l'époque la maison de Savoie n'a pas de politique diplomatique avec les rois de France. Hugues aurait pu être le procureur des Savoie à Rome afin obtenir les dispenses nécessaires pour Guillaume qui est trop jeune pour accéder à l'épiscopat et qui cumule sa charge avec une prébende canoniale ${ }^{131}$. Mais dans le Scriptum, Hugues parle de Rome en disant " On m’a dit que la curie ne demande pas d'argent pour accorder une lettre bénéficiale ${ }^{132}$. »Ceci semble indiquer qu'il n’a jamais été à Rome dans les années 1230.

L'hypothèse que nous favorisons est la suivante. Larchevêque de Vienne depuis 1218 est Pénergique Jean de Bernin ${ }^{133}$. Ce prélat réformateur encourage ses clercs à faire des études. En 1221, il pousse le chapitre Saint-Maurice à adopter les règles de non-résidence qui permettent aux clercs qui partent faire des études de théologie de conserver l'intégralité de leurs revenus ${ }^{134}$. On peut penser que Jean de Bernin a incité ou financé de jeunes clercs prometteurs de son diocèse pour qu'ils se rendent à Paris ou à Bologne ${ }^{135}$. Ces clercs se sont rangés sous lautorité d'un jeune maître de même origine géographique. On sait que c'est courant pour les maîtres ès arts et ceux qui commencent les longues études de théologie de s'occuper d'un groupe de jeunes étudiants souvent de la même origine géographique qu'eux, en les logeant et en leur servant de mentor ${ }^{136}$. Hugues a pu diriger une pédagogie, une maison d'étudiants originaires du diocèse de Vienne. Il aurait eu parmi ces pensionnaires Humbert de Romans et Guillaume de Savoie. La présence d'un rejeton d'une famille de la haute noblesse sur les bancs de luniversité peut paraître improbable. Cependant, lorsqu'un autre frère de Guillaume, Philippe (il deviendra par la suite archevêque de Lyon), qui lui a succédé sur le siège de Valence souhaite être délié de sa charge, il avance dans sa requête au pape qu'il souhaite faire des études ${ }^{137}$. Même s'il ne s'agit là que d'un prétexte, cela montre qu'il n'était

${ }^{131}$ Dans le chapitre sur la simonie du Scriptum, on trouve un passage qui est absent des sources utilisées par Hugues et qui pourrait être interprété comme une allusion au cas de Guillaume : « Nec presbiter ante xxx. : quod tricesimus annum congruus sit predicationi et sacerdotibus ordinandis et episcopis consecrandis multis exemplis sacre scripture ostendi potest. [...] Tamen circa religiosas personas pro neccessitate servitii consuevit Ecclesia dispensare et in illis potissime personis in quibus morum maturitas brevioris etatis spacium recompensat ", mss. Paris, BnF, lat. 3073, f. 141v ; lat. 3406, f. 128v. Parmi ces " gens très puissants chez qui la maturité des mœurs compense la jeunesse » pour qui léglise peut accorder une dispense de la règle qui interdit d'être consacré évêque avant lâge de 30 ans, nous verrions bien Guillaume de Savoie .

${ }^{132}$ Texte cité infra, p. 37, n. 151.

${ }^{133} \mathrm{U}$. Chevalier, Jean de Bernin archevêque de Vienne (1218-1266) : mémoire historique, Paris, 1910.

${ }^{134} \mathrm{U}$. Chevalier, Actes capitulaires de l'église Saint-Maurice de Vienne, Vienne, 1875, p. 21.

${ }^{135}$ Dans cette génération de jeunes clercs savoyards envoyés aux universités, on peut aussi ajouter Hostiensis qui est le contemporain d'Humbert de Romans. Il faut noter qu'Hostiensis dans son testament fonde un service liturgique au chapitre Saint-Maurice pour Jean de Bernin, Hugues de Saint-Cher et lui-même (A. Paravicini Bagliani, I testamenti dei cardinali del Duecento, Rome, 1988, p. 139). Il semble qu'il s'agisse d'un autre service que celui fondé pour Hugues de Saint-Cher à sa mort (U. Chevalier, Actes capitulaires, op. cit., p. 119, n. 29). Un autre trait d'une culture commune de groupe est la double attirance pour les chartreux (très présents dans larc alpin) et les dominicains : Humbert de Romans voulait devenir chartreux avant de choisir lordre dominicain (GÉrard de Frachet, Vitae Fratrum, op. cit., p. 170-71); Hostiensis dans la préface à sa Summa Aurea (Lyon, 1537 [reprint Aalen, 1962]) donne comme trois types de religieux : les chartreux, les dominicains et les franciscains. Sur l'existence d'autres liens entre Hostiensis et Hugues de Saint-Cher voir dans ce volume, la communication du P. P.-M. Gy, p. 23, ainsi que la nôtre, p. 29.

${ }^{136}$ Sur les pedagogie ou burse, sur lesquelles on ne possède des documents que pour le bas Moyen Âge, voir $A$ History of the University in Europe, t. 1, University in the Middle Ages, éd. H. De Ridder-Symoens, Cambridge, 1992, p. 218-219.

${ }^{137}$ Reg. Innocent IV, n 659 ; Gallia Christiana, t. XVI, preuves, col. 817. 
pas impensable qu'un fils du comte de Savoie se rende à l'université de Paris.

En tout cas, si l'on accepte l'hypothèse qu'Hugues dirigeait une pédagogie d'étudiants du diocèse de Vienne, alors Humbert de Romans pouvait parler de lui comme 'son maître' sans que cela signifie qu'il était son enseignant en droit canonique.

\section{La culture juridiQue d’Hugues d’après son Commentaire sur les Sentences}

Si Hugues avait été expert en droit canonique, on peut s'attendre d'autre part à en trouver une trace dans ses écrits théologiques. Cette idée se heurte néanmoins à un obstacle préliminaire. Quelle est la culture d'un enseignant en droit canonique à Paris dans les années 1220 ? Le texte des Vitae Fratrum est une preuve parmi d'autres qu'il existait un enseignement de droit canonique dans la capitale capétienne à cette époque. Néanmoins, nous ne savons rien des canonistes parisiens actifs dans ces années, ni n'avons de trace d'une quelconque production littéraire. Certes, dans le dernier quart du $\mathrm{XII}^{\mathrm{e}}$ siècle et au début du XIII ${ }^{\mathrm{e}}$ siècle, Paris est le centre de gravité des écoles dites « anglo-normandes » et « françaises » qui produisent des contributions originales à la doctrine canonique. Les derniers feux de lécole française sont ceux du maître Petrus Brito qui ne semble pas être actif après 1205 et plus modestement, dans le travail qui conduit à la recension dite parisienne de la Compilatio Tertia (vers $1210)^{138}$. L'éclipse du droit canonique à Paris est brutale. Elle est difficile à expliquer à moins de la mettre en regard de Pascension de Pastre bolonais ${ }^{139}$.

L'examen du Commentaire sur les Sentences d'Hugues, le Scriptum, révèle néanmoins moins une doctrine canonique obsolète qu'un savoir d'une autre nature. Nous avons mené notre enquête sur les distinctions traitant de la simonie car il s'agit d'un sujet abondamment traité dans le droit canonique et où Hugues aurait pu faire appel à une culture non théologique. La lecture du chapitre sur la simonie (lib. 4 d. 25) confirme pourtant les observations d'Alain Boureau sur le traité du mariage ${ }^{140}$. Le Scriptum est un assemblage relativement bâclé des travaux des théologiens en vogue lors des études d'Hugues. À l'heure où il rédige son chapitre sur la simonie, le maitre dominicain a ouvert sur sa table de travail la Glose sur les Sentences d'Alexandre de Halès, la Summa Aurea de Guillaume d'Auxerre et la Somme sur les Sacrements de Guy d'Orchelles. Il organise ensuite cette matière en quatre parties ${ }^{141}$. Il introduit et annonce son plan puis traite de la simonie en général en décalquant la présentation d'Alexandre de Halès. La majeure partie du chapitre est ensuite consacrée à des questions casuistiques (Commet-on la simonie par la seule volonté? Peut-on prêcher pour des biens matériels? Estce que les chanceliers et les notaires qui reçoivent de largent pour le scellement des actes

\footnotetext{
${ }^{138}$ A. Lefebvre-Teillard, «Petrus Brito legit? Sur quelques aspects de lenseignement du droit canonique à Paris au début du xiII ${ }^{\mathrm{e}}$ siècle ", Revue historique de droit français et étranger, 79 (2001), p. 153-177); K. Pennington, "The French recension of Compilatio tertia », Bulletin of Medieval Canon Law, 5 (1975), p. 53-71 (ici p. 68-69) [repris dans K. Pennington, Popes, Canonists and Texts 1150-1550, Variorum, 1993].

${ }^{139}$ A. Gouron, "Une école ou des écoles? Sur les canonistes français (vers 1150 - vers 1210) ", dans Proceedings of the Sixth International Congress of Medieval Canon Law, éd. S. Kuttner et K. Pennington, Vatican, 1985, p. 223-240.

${ }^{140}$ Voir sa contribution dans ce volume. Il faut remarquer que dans le traité sur le mariage, Hugues utilise une source juridique : la Somme sur le mariage de Tancrède.

${ }^{141}$ Par simplification, nous laissons de côté le fait que le Scriptum assemble des gloses sur le texte de Pierre Lombard et un commentaire.
} 
pèchent? Hugues reprend les casus à Alexandre de Halès, Guillaume d'Auxerre et Gui d'Orchelles. Quelquefois, il résume ou laisse de côté certains pro ou contra mais les solutions sont toujours identiques à celles de ses sources. Hugues termine à son habitude le chapitre en quittant le champ théologique en incluant une distinction à usage pastorale sur les cinq pièces de la monnaie de simonie et des vers mnémotechniques sur le même sujet. Le patchwork des sources antérieures occupe $75 \%$ du chapitre. Ceci donne une idée de la dépendance d'Hugues vis-à-vis de ses maîtres ${ }^{142}$.

On se concentrera, dès lors, sur les modestes modifications et ajouts qu'Hugues opèrent sur les sources afin de mieux cerner sa culture juridique. Il semble que lon peut en conclure qu'il fait preuve moins d'une intime familiarité avec la doctrine des décrétistes que d'un esprit pratique. On en donnera quelques exemples. Alexandre de Halès définit les spiritualia en reprenant une distinction classique provenant de la Somme sur le Décret de Rufin ${ }^{143}$. Les spiritualia sont de quatre sortes : les dons du Saint-Esprit qui ne peuvent se vendre ni de droit, ni de fait; les sacrements qui ne peuvent se vendre de droit mais le sont souvent de fait, les droits ecclésiastiques, comme les dîmes, qui ne peuvent se vendre de droit et les objets liturgiques qui peuvent se vendre de droit ${ }^{144}$. Hugues reprend le texte d'Alexandre en remarquant néanmoins que les droits ecclésiastiques doivent plutôt être dits annexes au spirituel et qui s'ils ne peuvent être vendus de droit, ils le sont souvent de fait ${ }^{145}$. Dans cette modeste réécriture, on voit deux des traits à l’ouvre chez Hugues : un goût du concret et une réutilisation de concepts de base du droit. Ainsi Hugues réemploie à de nombreuses reprises Pidée de droits annexes au spirituel, une formulation très courante mais qu'Alexandre de Halès n'avait pas employée ${ }^{146}$. Cependant, il ne faudrait pas déduire de cette juridicisation du vocabulaire qu'Hugues est un fin connaisseur du droit savant canonique. Il paraît même sur certains points être moins au point que ses sources. Ainsi Alexandre de Halès avait écrit que le juge peut se faire payer pour l'exsecutio, c'est-à-dire l'exécution d'un jugement ${ }^{147}$. Il fait ici une rapide allusion aux pratiques qui statuent que si la justice ecclésiastique est gratuite, les frais de procédure ne le sont pas. Hugues en reprenant ce passage saute ce terme de procédure romano-canonique qu'il ne devait pas comprendre et réécrit le passage en pensant qu'il ne s'applique qu'au juge séculier ${ }^{148}$.

\footnotetext{
${ }^{142}$ Sur la position que reprend Hugues, voir ici même p. 18.

${ }^{143}$ Rufin,Summa Decretorum (1164), ad C. 1 q. 1, éd. H. Singer, Paderborn, 1902 (repr. Aalen, 1963), p. 200201. Nous préparons un article sur le concept de spiritualia en droit canonique [ Spiritualia et Temporalia : Naissance d'un couple ", Zeitschrift der Savigny-Stiftung für Rechtschichte. Kanonistische Abteilung, 123/92 (2006), p. 224-287].

${ }^{144}$ Alexandre de Halès, In Sent., 1. IV, d.25, t. IV, Quaracchi, 1957, p. 444.

145 «Item dicitur spirituale ius percipiendi dona. Sed magis proprie dicitur hoc annexum spirituali et hec spirituale de iure vendi non potest licet de facto sepe vendatur ut legitur Causa prima q. III $^{a}$ ca., Si quis obiecerit (C. 1. q. 3 c. 2 ) ", mss. Paris, BnF, lat. 3073, f. 140v; lat. 3406, f. 127v.

${ }^{146}$ Le premier à dire que la dîme est un droit annexe aux spiritualia est Étienne De Tournai, Summa Decretorum (1165-66), ad C. 1 q. 1, éd. J. F. Schulte, Giesse, 1891 (repr. Aalen, 1965), p. 121-122. Annexe ne signifie pas 'secondaire' mais 'nécessairement lié.'

${ }^{147}$ Alexandre de Halès, In Sent., 1. IV, d. 25, éd. cit., p. 442.

${ }^{148}$ « Item sententia iudicis res spirituale vel annexa spirituali unde Sap. diligite iusticiam qui iudicatis terram (Sap. 1.1) sed constat quod iudices seculares quando vendunt sententias suas vel iusticias non committunt symoniam, ergo voluntas emendi vel vendendi adnexum spirituali non est symonia. [...] Ad tercium dicimus quod iusticiam quam facit iudex secularis non est res spiritualis nec adnexa spirituali, unde nec symonie reus est
} 
Un autre indice de la familiarité qu'avait Hugues avec la justice seigneuriale de son temps est une glose à un casus repris de Guy d'Orchelles. Guy posait la question de savoir si un chancelier pouvait demander de largent pour sceller un acte et y répondait en avançant qu'un chancelier pouvait se faire rembourser son travail et ses frais (parchemin, plomb) ${ }^{149}$. Il s'agit dans les milieux universitaires d'un casus classique qui trouve son origine dans les polémiques autour de la gratuité de la licentia docendi ${ }^{150}$. Hugues glose la solution de Guy en notant que le problème ne concerne pas uniquement les chanceliers mais aussi les notaires et que le coût doit se calculer de manière juste en considérant lautorité du scelleur et limportance de lacte : un chevalier ne peut pas demander le même tarif que le pape et un acte mineur est moins cher qu'un acte important. Certains prélats ont même mis en place des tarifs ${ }^{151}$. La réécriture d'Hugues du texte de Guy d'Orchelles lui donne un nouveau contexte : celui d'une société où lenregistrement des actes et la juridiction gracieuse prennent une place grandissante.

Observateur des pratiques judiciaires de son temps, Hugues a aussi le goût des raisonnements sur la propriété partagée. Alexandre de Halès expliquait que Dieu ne peut pas commettre d'actes de simonie car il est le plein propriétaire (dominus) des biens de léglise alors que les prélats n'en sont que les gestionnaires (dispensatores) ${ }^{152}$. Réécrivant le passage, Hugues glose Alexandre en indiquant que Dieu a le dominium sur les biens de léglise et il propose une belle image pour expliquer que les prélats sont des gestionnaires de la même façon qu'un domestique qui donne une aumône à la porte de la maison sur lordre de son maître ${ }^{153}$. Le domestique ne possède en rien la pièce de monnaie, il n'est qu'un messager entre son maître et le pauvre. Mais les compétences d'Hugues en droit romain restent fragmentaires. Discutant la possibilité pour Jacob d'acheter le droit d'aînesse d'Esaü, Alexandre de Halès expliquait que le plat de lentilles avait payé la quieta possessio du droit d'aînesse et que donc l'Église pouvait racheter des dîmes aux laïcs ${ }^{154}$. Alexandre reprenait là la distinction romaine entre possession

quando vendit. Sed peccat ex avaricia quia ad hoc constitutus est iudex ut omnibus libere iusticiam faciat pro pacis unitate servanda ", mss. BnF, lat. 3073, f. 140v ; lat. 3406, f. 127v-128r.

${ }^{149}$ Guy D'Orchelles, Summa de Sacramentis, $\$ 206$ : «Utrum cancellarii possint recipere pecuniam pro littere sigillandis. Item, queritur de cancellariis qui recipiunt pecuniam pro litteris sigillandis. Ad quod dicimus quod propter litteras de beneficiis nihil debent recipere, sicut nec Romana Ecclesia. Pro aliis autem negotiis bene potest pro suo labore, pro plumbo, pro pergameno et huiusmodi », éd. D. et O. VAn DEN Eynde, NewYork, 1953, p. 192.

${ }^{150}$ G. Post, K. Giocarinis et R. Kay, « The Medieval Heritage of a Humanistic Ideal : Scientia donum Dei est, unde vendi non potest $»$, Traditio 11 (1955), p. 196-234.

151 « Item queritur $<\mathrm{si}>$ de cancellariis et notariis qui recipiunt peccuniam pro litteris sigillandis utrum peccent? Dicimus quod pro labore suo et pro pergameno et pro aliis huiusmodi secundum iustam estimationem potest recipere, pensata etiam sigilli auctoritate et negocii utilitate. Non enim tamen accipiendis est pro sigillo militis quantum pro sigillo pape, negocio existente pari. Similiter nec tamen accipi potest pro negocio parvo quantum pro magno. Sed quoniam sepe fallitur humanum iudicium, ideo quidam prelati sigilli sui precium taxaverunt, scilicet unum vel duos vel tres secundum iustam exstimationem patrie. Tamen de litteris pro beneficiis optinendis non est tunc accipere peccuniam quod in romana curia ut audivimus observatur ", mss. BnF, lat. 3073, f. 141v; lat. 3406, f. 128r.

${ }^{152}$ Alexandre de Halès, In Sent., 1. IV, d. 25, éd. cit., p. 442.

${ }^{153}$ « Notandis quod bona spiritualia ecclesie aliter sunt Dei aliter prelati. Dei sunt ut domini unde hiis facere potest quicquid ei placuerit vel dare vel vendere vel commutare sine omni symonia, aliter enim non haberet plenum dominium eorum. Prelati sunt ut dispensatoris tamen unde non potest ea vendere vel commutare pro voluntate sua sed tamen ut eis vult dominus erogare quasi minister qui portat elimosinam pauperi ad ianuam mendicandi ", mss BnF lat. 3073, f. 140v; lat. 3406, f. 128r.

${ }^{154}$ AleXandre de Halès, In Sent., 1. IV, d. 25 : «Si vero queretur de iniuste suspenso, utrum possit pecunia 
et propriété reprise par le droit canonique pour expliquer qu'un laïc ne peut avoir un droit de propriété sur une dîme mais simplement un droit de possession toléré par l'Église. En reprenant ce passage, Hugues confond propriété et possession et équivaut usufruit et quieta possessio $^{155}$. Il prétend ensuite avoir lu dans une décrétale d'Alexandre III que le rachat de la dîme équivalait au rachat de l'usufruit alors que le pape avait soigneusement utilisé le vocabulaire de la possession distinguant entre le corpus et l'animus.

La confusion entre possession et propriété est symptomatique des pratiques du temps. La jurisprudence tend à les mélanger. Le travail des sources qui est à l’ouvre dans le chapitre sur la simonie du Scriptum révèle ainsi chez Hugues des talents de gestionnaire et une culture de droit notarial. Hugues a dû acquérir ses capacités dans sa jeunesse. Le Dauphiné et la vallée du Rhône sont des régions pénétrées très tôt par le droit notarial ${ }^{156}$.

\section{Le droit Canonidue dans les duestions disputées d'Hugues de Saint-Cher sur la PLURALITÉ DES BÉNÉFICES}

Dans les années 1235-1240, Hugues dirige plusieurs questions disputées sur la question de la pluralité des bénéfices. On connaît trois états de ce texte qui révèle un usage de sources juridiques absentes du Scriptum ${ }^{157}$. Il est évidemment difficile de déterminer quelle a été la part du maître et celle de ses assistants dominicains dans le travail de composition. On découvre en tout cas dans ces textes de références au droit d'un nouveau type.

Il y est fait usage non seulement du Liber Extra de 1234 mais aussi d'une collection canonique antérieure, la Compilatio Secunda. La question renvoie aussi explicitement à des opinions de maîtres bolonais actifs dans les années 1210-1220 : on y trouve une citation qui utilise deux sigles de maîtres bolonais : Lau. et Io. ${ }^{158}$. Le sigle Lau. désigne certainement Laurent

redimere exsecutionem sui officii : - quod viderunt per hoc quod dictum de Iacob, qui emit primogenita; et preter hoc, Ecclesia non peccat redimendo decimas - respondemus : 'Sententia pastoris, sive iusta sive iniusta, timenda est'; et quia reconciliatio est res spiritualis, non potest redimere. Iacob autem proprie ius suum non redemit, ses quietam sui possessionem ", éd. cit., p. 443.

155 «Dicimus quod ius primogeniture nullo iure obligatum fuit Esau nec unquam habuit Esau ius primogeniture licet usum sive fructum ad tempus habuit et Iacob dando ei lentis edulium non tamen ius suum redemit quam quietam iuris sui possesionem comparavit. Similiter dicimus de decimis laici enim non habunt ius percipiandi decimas nec habere possunt sed usum fructus violenter tenent unde cum ecclesia peccuniam dat pro decimis magis fructus decimarumquam ius redimit. Unde subtiliter innuit quedam decretalis Alexandri quod non licet redimere quod non licet emere; fructus vero decimarum licet vendere et emere et redimere sed non ius proprie loquendo ", mss. BnF, lat. 3073, f. 141r ; lat. 3406, f. 128r. Nous n’avons pas retrouvé la décrétale d'Alexandre III dont Hugues parle, il s'agit peut-être de Latran III, c. 14 = (X 3.3.19) où le pape explique qu'un laïc ne peut vendre à un autre une dîme car il n'en possède pas l'animus.

${ }^{156}$ Sur un exemple de droit notarial de cette période G. Giondanengo, «Bertrand du Pont, notaire d’Avignon et son formulaire ( ${ }^{\mathrm{e}}$ quart du XIII ${ }^{\mathrm{e}}$ siècle) ", Annales de l'Université des sciences sociales de Toulouse, 24 (1976), p. 317-27 (repris dans ID., Féodalités et droits savants dans le Midi médiéval, Londres, 1992).

${ }^{157}$ Sur ces questions disputées voir supra, p. 26 et l'Annexe suivante.

158 "Item Lxx di., Sanctorum (D. 70, c. 2) expresse dicit quod unus non debet esse canonicus prebendarius in diversis ecclesiis et quod obiectum est de glo. Lau que dicit quod intelligitur de canonicis regularibus. Quod etiam potest <obiectare $>$ per hoc quia in principio dicitur clericus in ecclesia in qua intitulatus est 'perpetuo perseveret', dicendus quod ipse textus contrarius est glose Lau. quia nullus canonicus regularis dicitur canonicus prebendarius et quod dicit 'perpetuo perseveret' intelligitur id est iugitur ut deservat, id est ad aliam non transeat vel 'perpetuo' id est dum vivit glo. Io. ", ms. Douai, BM 434, f. 125vb. Dans lultime état de la question, largument est réécrit de la manière suivante : «Laurentius exposuit de canonicis regularibus quod manifeste 
d'Espagne. Le sigle Io. est plus ambigu car il peut renvoyer à cette époque à deux maîtres bolonais : Jean le Teutonique et Jean de Galles ${ }^{159}$. La question d'Hugues de Saint-Cher ne donne aucune indication sur la provenance de ces opinions. Il existe deux possibilités. Ces gloses peuvent orner soit le Décret de Gratien soit les Compilationes Antique. Les deux solutions sont envisageables. Laurent d'Espagne a assemblé un influent apparat au Décret, la Glossa Palatina mais il est aussi lauteur de commentaires sur la Compilatio Tertia. Jean le Teutonique a aussi glosé tant le Décret que la Compilatio Tertia. Jean de Galles, quant à lui, n’a pas laissé, semble-t-il, de gloses sur le Décret mais il a commenté tant la Compilatio Secunda que Tertia.

La question d'Hugues cite aussi le texte clef dans le débat sur la pluralité des bénéfices, le canon de Latran IV, De multa. Néanmoins, alors que ce canon était principalement le point de départ d'une controverse sur les limites des pouvoirs de dispense de l'évêque, Hugues allègue ce canon pour s'opposer à ceux qui linterprétaient en suivant les brisées du canoniste Vincent d'Espagne. Vincent remarquait qu'Innocent III avait dans De multa interdit le cumul des bénéfices avec charge d'âmes sans dispense et il en déduisait que le cumul des bénéfices sans charge d'âmes - dans le jargon des canonistes un bénéfice simple — était tacitement autorisé $^{160}$. Hugues rejette largument en s'excipant d'autres autorités pour avancer que le cumul de bénéfices simples est illégal ${ }^{161}$. Dans ce passage, Hugues cite les décrétales en se référant aux Compilationes Antique alors qu'il aurait très bien pu utiliser le Liber Extra. Ce détail révèle qu'il adapte une glose trouvée dans les marges d'un exemplaire des Compilationes Antique. Quel maître suivait-il ? Il ne s'agit pas de Raymond de Peñafort qui commente De multa de manière différente ${ }^{162}$. Le candidat le plus probable est Damase qui a des positions proches d'Hugues ${ }^{163}$. Un peu plus loin, dans la détermination Hugues défend une position qui n'est pas sans rappeler non plus des thèses soutenues par Damase ${ }^{164}$.

Ces indices mis bout à bout montrent qu'au moment où Hugues disputait sur la pluralité

est contra litteram quia ipsi non sunt prebendarii et ibi loquitur ius de prebendariis ", éd. STEGmülLer, $o p$. cit., p. 192. Nous n'avons pas pu retrouver cette opinion de Laurent d'Espagne qui restreint lapplication de Sanctorum aux seuls chanoines réguliers dans les commentaires sur ce canon de la Glossa Palatina (mss. Vatican, Pal. lat. 658, f. 18 , Reims, BM 680, f. 42 $\mathrm{v}^{\circ}$ ), ni dans les gloses signées Lau. de la deuxième couche du ms. Paris, BnF, lat. 15393, f. $53 \mathrm{r}^{\circ}$ ni dans la première version de la glose ordinaire de Jean le Teutonique (ms., Paris, BnF lat. 3905, f. 45r).

${ }^{159} \mathrm{La}$ bibliographie sur les canonistes médiévaux est aujourd'hui extrêmement dispersée. Une nouvelle histoire du droit canonique médiéval est en cours de rédaction par un collectif d'auteurs (History of Medieval Canon Law, éds. W. Hartmann et K. Pennington, Washington, 1999-). Un volume sera consacré à un répertoire des canonistes entre 1140 et 1500 . Il en existe une version de travail sur linternet : http ://faculty.cua.edu/penningk/biobibl.htm

${ }^{160}$ Vincent D’Espagne, Apparatus super Constitutiones Concilii quarti Lateranensis, ad c. 29, éd. A. García y García, Constitutiones Concilii quarti Lateranensis una cum Commentariis glossatorum, Vatican, 1981, p. 324-25.

${ }^{161}$ «Ad id quod XIIII ${ }^{\circ}$ obiicitur de Lateranenses concilio quod prohibet illum qui habet sufficiens beneficium recipere aliud beneficium habens curam animarum unde videtur concedere quod aliud beneficium ubi non est cura adnexa potest recipere. [...] dicendus quod papa ubi tacuit de simplici beneficio quia et si ibi non prohibuit tamen alibi in multis locis prohibuit : extra II De prebendis et dignitatibus, Cum non ignores $\left(2^{\mathrm{a}}\right.$ Comp. 3.4.1); extra III De concessione ecclesie non vacantis, Litteras (3a Comp. 3.8.6) et Lxx D., Sanctorum (D. 70 c. 2) », ms. Douai, BM 434., t. II, f. 125v-126r. Largument pro auquel Hugues répond manque dans le manuscrit de Douai.

${ }^{162}$ Raymond de Peñafort, Summa de casibus, 13, éd. Lyon, 1718, p. 263.

${ }^{163}$ Damase, Apparatus super Constitutiones Concilii quarti Lateranensis, ad c. 29, éd. García y García, op. cit., p. 433.

${ }^{164}$ Supra, p. 28. 
des bénéfices, il devait utiliser tant un Décret de Gratien qu'un exemplaire des Compilationes Antique avec des gloses bolonaises ainsi qu'un exemplaire du Liber Extra. Vraisemblablement, il s'agit de manuscrits qui avaient appartenu à un ancien étudiant de Bologne qui, en entrant dans Pordre dominicain, avait placé dans la bibliothèque commune de Saint-Jacques les ouvrages qu'il avait acquis durant ses études.

Tant les données biographiques que l'étude des œuvres théologiques d'Hugues ne permettent pas d'appuyer laffirmation de Quétif et Échard. Hugues ne fut pas enseignant en droit canonique à Paris avant d'entrer dans l'ordre dominicain. Néanmoins, contrairement à d'autres théologiens contemporains, il n'est nullement hostile aux canonistes ${ }^{165}$. Il possède une culture de praticien du droit qu'il n'hésite à mettre à jour lorsque le besoin s'en fait sentir. Il s'inscrit dans la tradition encyclopédique du premier ordre dominicain. Il témoigne aussi d'une sensibilité de gestionnaire qui est certainement une des raisons de sa brillante carrière.

\section{ANNeXe : Le Dossier Des TeXTeS De LA QUERELLe De I235-I 238}

Nous ferons ici un premier inventaire des textes écrits lors de la querelle de 1235-38 ou en relation avec celle-ci. Il faudrait procéder à une édition critique de l'ensemble pour consolider ou infirmer les quelques hypothèses philologiques que nous lançons.

\section{Questions disputées par Hugues de Saint-Cher}

On peut distinguer au moins trois versions de questions disputées par Hugues de SaintCher sur la pluralité des bénéfices. Nous les désignerons par commodité $A, B$ et $C$. $C$ n'est pas lui-même une question mais un groupe de questions sur les bénéfices ecclésiastiques qui se trouve en appendice à un manuscrit bâlois du Scriptum ${ }^{166}$. Le manuscrit de Bâle comporte, de plus, une très courte question de Geoffroy de Bléneau sur la pluralité des bénéfices et un autre fragment de question traitant de la dîme. Friedrich Stegmüller a édité l'ensemble en pensant qu'il s'agissait du texte de la première dispute de $1235^{167}$.

La table qui ouvre $C$ propose un plan en sept parties :

- $C_{1}$ Peut-on donner un bénéfice à un laïc et à un clerc?

- $C_{2}$ Peut-on, de manière générale, recevoir plusieurs bénéfices avec ou sans charge d'âmes?

- $C_{3} S$ Si lon admet que celui qui reçoit plusieurs bénéfices pèche, celui qui accorde ces bénéfices pèche-t-il?

- $C_{4}$ Peut-on prédiquer qu'il est illicite de posséder plusieurs bénéfices?

- $C_{5}$ Si un évêque a pour opinion qu'il est illicite de posséder plusieurs bénéfices, peut-il envoyer, sans pécher, prêcher un pluraliste?

- $C_{6}$ Si un pluraliste se confesse, est-ce que son confesseur peut labsoudre même s'il ne veut pas résigner ses bénéfices sauf un?

\footnotetext{
${ }^{165}$ Sur lopposition de certains théologiens parisiens aux juristes, supra, p. 22.

${ }^{166}$ ms. Bâle, Univ. Bibl, Cod. B II 20, f. 66-67.

${ }^{167}$ F. Stegmüller, «Die neugefundene Pariser Benefizien-Disputation des Kardinals Hugo von St. Cher OP. », Historisches Jabrbuch, 72 (1953), p. 176-204.
} 
- $C_{7}$ Un papelard (papilardus) tient un seul bénéfice mais de grand revenu et il dépense peu et accumule beaucoup d'argent. Un autre possède plusieurs bénéfices mais dépense largement. Lequel de ces deux sera le plus mal traité en enfer après la mort ${ }^{168}$ ?

Le reste du manuscrit ne répond pas aux promesses de la table. $C_{1}$ est court mais complet (contra, pro, determinatio, ad obiecta); $C_{2}$ ne comprend que les contra et pro; $C_{3}$ constitue le cœur de $C$ dans son entier : elle comporte des pro et contra, une longue determinatio mais les ad obiecta renvoient aux contra de $C_{2}$ et pas à ceux de $C_{3} ; C_{4}$ est squelettique avec un argument contra et une détermination; $C_{5}, C_{6}$ et $C_{7}$ manquent.

On trouve dans deux autres manuscrits allemands la determinatio de $C_{3}$ dans une forme différente de celle transmise par le manuscrit de Bâle et dans lun de ces manuscrits cette solution est attribuée à Hugues de Saint-Cher ${ }^{169}$. De plus les dépouillements de collections de questions disputées réalisées pour l'édition de la Summa Fratris Alexandri révèlent de nouveaux témoins. Ainsi dans deux manuscrits conservés à Assise ${ }^{170}$, on trouve une question anonyme $B$ qui paraît composée des pro et contra de $C_{2}$ et de la determinatio de $C_{3}$ sous une forme différente et, on imagine, des ad obiecta de $C_{3}$. Il faut aussi vraisemblablement identifier une question anonyme conservée dans un manuscrit de Trêves avec $B^{171}$.

Enfin, dans les manuscrits Assise, Bibl. commun., 138, f. 234v-236r et Douai, Bibl. mun., 434, t. II, f. 124r-126r se trouve une autre question anonyme $A$ dont lintitulé dans le manuscrit de Douai est : Quaesitum est utrum liceat simpliciter recipere vel retinere plura beneficia. Les pères de Quaracchi avaient déjà suggéré le rapprochement entre la question du manuscrit d'Assise et celle de Douai et une transcription complète de la question de Douai permet de confirmer leurs suggestions. Ce manuscrit en trois volumes est une mine de textes produits à l'Université de Paris dans les années $1230^{172}$. Il comporte en particulier 572 questions disputées ${ }^{173}$. On ne peut en attribuer qu'une faible partie. Cet échantillon révèle une première vague de maîtres qui sont actifs dans les années précédant la grève (Guillaume Durham, Guillaume d'Auxerre, Geoffroy de Poitiers) et une deuxième vague qui enseignent pendant et juste après la grève (Hugues de Saint-Cher, Jean de Saint-Gilles, Pierre de Bar). On ne trouve pas de questions de maîtres qui commencent à leur régence après 1232 comme Guéric de Saint-Quentin ou Jacques de Dinant. D’autre part, le manuscrit comprend lunique témoin de la Summa Duacensis qui est, comme la montré Nicolas Wicki, une adaptation sinon de la Summa de Bono, du moins d'une version préparatoire de la Somme de Philippe de Chancelier que son éditeur date de $1228^{174}$. Tout concorde pour placer l'essentiel du travail de composition des tomes I

\footnotetext{
${ }^{168}$ STEGMüLLER, op. cit., p. 184.

${ }^{169}$ mss. Einsiedeln, Stiftsbibl., 275, f. X et Osnabrück, Ratsgymnasium, C 1, f. 117 cf. STEGmüller, op. cit. qui n'a collationné que le manuscrit d'Osnabrück. Il faut laisser en suspens la question de savoir si les déterminations de ces deux manuscrits correspondent à l'état $C$ ou $B$ de la question d'Hugues.

${ }^{170}$ Summa Fratris Alexandri, t. 4 (1948), Prolegomena, p. cCxxıII-CCXxıv et passim. Il s'agit des mss. Assise, Bibl. commun., 138, f. 236 et Assise, Bibl. commun., 182, f. 5.

${ }^{171}$ ms. Trêves, Stadtbibl., 922, f. 165r-169r découvert par A. STICKLen, « Decretista Germanica adaucta ", Traditio, 12 (1956), p. 593-605, ici p. 603. Les extraits de la détermination publiés par K. Pennington, « The Canonists and Pluralism..." ", op. cit., p. 44 n. 43 correspondent à la version des manuscrits d'Assise.

${ }^{172}$ Voir en dernier lieu R. Quinto, «Il codice 434 di Douai, Stefano Langton e Nicola di Tournai », Sacris erudiri, 36 (1996), p. 233-361 qui liste la bibliographie et récapitule les questions éditées.

${ }^{173}$ P. Glorieux, « Les 572 Questions du manuscrit de Douai 434 », RTAM, 10 (1938), p. 123-157; 225-267.

${ }^{174}$ Philippe le Chancelier, Summa de Bono, éd. N. Wicki, Berne, 1985.
} 
et II du manuscrit autour de 1230.

On peut jeter quelques lumières supplémentaires sur l'élaboration de lensemble. 74 questions du manuscrit sont signées d'une mystérieuse initiale G. Le père Doucet a proposé, de manière convaincante, de comprendre ce G. non pas comme Pinitiale d'un maître mais du compilateur du manuscrit ${ }^{175}$. Ce G. aurait été Pélève de Philippe le Chancelier à Paris. En effet, non seulement il copie ou adapte de larges extraits de la Summa de Bono mais il insère dans son recueil un sermon très vraisemblablement prononcé à la curie par Philippe lors de son élection ratée à lévêché de Paris en 1227-28 ${ }^{176}$. Par la suite, G. réside à Soissons comme Pindique un bout de texte noté dans une marge qui débute "L'an (12)41, j’ai prêché ainsi au peuple de Soissons lors du dimanche des Rameaux ${ }^{177}$."

Les questions de Douai sont copiées dans ce que lon pourrait appeler un carnet de notes, de plusieurs mains, sans souci de respecter les marges ou une quelconque mise en page. La question sur la pluralité des bénéfices forme néanmoins un cas à part. Elle se trouve dans un ensemble nommé $J$ par Glorieux qui comprend treize questions anonymes. $J$ forme une unité codicologique séparée, de trois cahiers, dont lun possède une réclame. Le premier folio de $J$ est un peu usé ce qui indique que le cahier a dû circuler de manière séparé avant d'être adjoint par G. dans son recueil. Enfin, le (ou les) scribe(s) de $J$ élargissent ou compriment parfois le module de leur écriture. Un détail qui montre que le scribe ne mettait pas au net des notes ou transposait d'un format à lautre mais cherchait à reproduire exactement les pages qu'il avait devant les yeux. De plus, alors que les questions de Douai se suivent dans le plus grand désordre thématique, $J$ présente une logique pédagogique. On y trouve sept questions, une pour chacun des péchés capitaux; la série étant interrompue par la question sur la pluralité des bénéfices. Puis deux questions roulent sur des sujets qui sont liés : le ravissement de Paul et la prophétie. La dernière question, incomplète, traite de limmortalité de l'âme. Palémon Glorieux avait remarqué que lune des questions sur les vices se retrouve à un autre endroit du manuscrit avec l'indication 'A.' Notant que $J$ comportait une question sur la pluralité des bénéfices, Glorieux prenait appui sur le texte de Thomas de Cantimpré pour avancer que A. serait Arnould de la Pierre. Mais, comme l'a montré Doucet, la question sur les bénéfices de $J$ s'oppose aux pluralistes; elle ne peut être d'Arnould ${ }^{178}$. Les pères de Quaracchi avaient une autre idée: A. serait Alexandre de Halès ${ }^{179}$. Mais, lédition des Questions disputées antequam esset frater d'Alexandre n'a pas permis de retrouver des recoupements avec aucune des questions de $\mathrm{J}^{180}$. Notre hypothèse consisterait à dire que A. n'est pas un maître régent mais un correspondant de G. qui la aidé à rassembler son matériel.

Si l'on admet que le manuscrit de Douai rassemble l'ensemble des questions disputées à Paris pendant quatre années scolaires alors on aboutit à une moyenne de quatorze questions par maitre régent par an, un nombre proche de celui des questions contenues dans J. Livret indépendant, copié en plusieurs exemplaires, $J$ est, à notre avis, ce que lon dénommerait

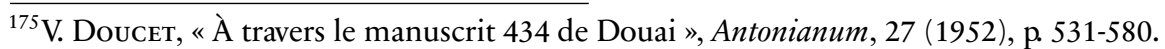

${ }^{176}$ N. WICKI, « Philipp der Kanzler und der Pariser Bischofswahl von 1227/28 », Freiburger Zeitschrift für Philosophie und Theologie, 5 (1958), p. 318-26.

${ }^{177}$ GlORIEUX, op. cit., p. 133, n 54.

${ }^{178}$ DOUCET, op. cit.

${ }^{179}$ Prolegomena, op. cit., p. cCXIII.

${ }^{180}$ AleXandre De Halès, Questiones disputatae 'antequam esset frater', Quaracchi, 1960.
} 
aujourd'hui un 'polycopié' des disputes conduites durant une année sous lautorité d'un des maîtres régents.

La transcription de la version $A$ de la question d'Hugues de Saint-Cher sur la pluralité des bénéfices permet de découvrir sa dépendance avec $C_{2}$ et $C_{3}$ sur de nombreux points même si les déterminations sont différentes. On retrouve dans $C_{2}$ et $C_{3}, 11$ des 20 pro de $A, 7$ contra sur 20 et 4 ad obiecta sur 20. L'un et lautre utilisent une référence à une glose de Laurent d'Espagne au Décret, une source plutôt originale pour des théologiens ${ }^{181}$. Notre conclusion est qu' $A, B$ et $C$ sont trois questions de Hugues de Saint-Cher et que $J$ est un 'polycopié' de l'école dominicaine de théologie ${ }^{182}$. Il faudrait évidemment poursuivre l'étude de cette thèse en transcrivant l'ensemble de $J$ et en comparant les questions avec le reste de l'œuvre d'Hugues.

Comment dater $A, B$ et $C$. Friedrich Stegmüller remarquait que lon ne trouve dans $C$ aucune mention de linterdiction de cumul dès que la somme des bénéfices dépasse 15 livres parisis que mentionne Thomas de Cantimpré. Il en déduisait que lon se trouvait donc devant le texte issu de la première phase de la dispute ${ }^{183}$. Mais, cette somme de quinze livres ne se retrouve dans aucune autre pièce du dossier et son absence ne peut être un critère de datation déterminant. Des trois états de la question, seul $A$ est aisément datable. $A$ utilise le Liber Extra et est donc postérieur à $1234^{184}$. L'un des ad obiecta de $A$ fait une allusion à un maître qui est certainement Philippe le Chancelier qu'il présente comme malade ${ }^{185}$. La question précède donc la mort de Philippe à la fin de 1236. $B$ représente certainement un état intermédiaire. $C$ est certainement postérieur à $A$, ne serait-ce que par ce qu'il en corrige les bourdes. Ainsi, $A$ attribuait une autorité au 'saint pape Grégoire écrivant à Eugène ${ }^{186}$. $C$ rectifie en 'saint Bernard à Eugène ${ }^{187}$. $C$ est aussi sans nul doute postérieur à $B$. Il scinde $B$ en deux, $C^{2}$ et $C^{3}$, afin de distinguer les volets juridique et peccamineux et de traiter non seulement le cas des pluralistes mais aussi celui des prélats qui tolèrent ou encouragent les pluralistes. La composition de $C$ n'est pas aboutie car le texte est tronqué, $C^{2}$ n'étant qu'un squelette de question et la réécriture de la determinatio que tente $C^{3}$ étant maladroite. $C$ nous paraît ainsi moins le reflet de questions orales qu'une tentative de synthèse d'un matériel antérieur.

\section{UNE QUESTION DISPUTÉE EN FAVEUR DU PLURALISME?}

Le manuscrit Prague, Bibl. univ., IV D. 13 comporte de nombreuses questions disputées par des maitres parisiens et en particulier par Guerric de Saint-Quentin ${ }^{188}$. On y trouve une ques-

\footnotetext{
${ }^{181}$ STEGmüller, op. cit., p. 192 et ms. Douai, t. II, f. 125v.

${ }^{182}$ Notons que dans le ms. Assise, $138 A$ et $B$ se suivent.

${ }^{183}$ STEGMÜLLER, op. cit., p. 182.

${ }^{184}$ Par exemple «(xi) Item, Extra III, De concessione prebende et ecclesie non vacantis, Litteris (X 3.8.9) », ms. Douai, t. II, f. 124r. Lénoncé du titre du chapitre correspond au Liber Extra et pas à la Compilatio Tertia $\left(3^{\mathrm{a}}\right.$ Comp. 3.8) où l'on trouve déjà cette décrétale.

${ }^{185}$ Cf., supra, p. 26.

${ }^{186}$ Ms. Douai, t. II, f. 124r.

${ }^{187}$ STEGMÜLLER, op. cit., p. 188.

${ }^{188}$ B.-G. GuYot, «Questiones Guerrici, Alexandri et aliorum magistrorum parisiensium », Archivum Fratrum Praedicatorum, 32 (1962), p. 1-119. Il s'agit de la question n. 89.
} 
tion anonyme sur la pluralité des bénéfices. D’après les fragments édités par le père Guyot, le maître semble prudemment en faveur du pluralisme ${ }^{189}$.

\section{Le Commentaire Aser cum pinguis, le traité De Collatione beneficiorum de Guillaume D'Auvergne ET SES SERMONS ANTI-PLURALISTES.}

Parmi les œuvres dominicaines parisiennes des années 1230, le Commentaire sur l'Apocalypse, Aser cum pinguis se fait l'écho des conflits anti-pluralistes. Ce texte fait partie de la nébuleuse des Postilles d'Hugues de Saint-Cher. Comme la montré Robert Lerner, ce commentaire, par la virulence de son eschatologie, ne correspond pas à une autre version du commentaire sur l'Apocalypse, Vidit Iacob, aussi attribuée à Hugues de Saint-Cher ${ }^{190}$. On peut aller encore plus loin dans la déconstruction d'Aser cum pinguis. Comme dans le reste de la Postille, lexégèse sur chaque chapitre juxtapose un commentaire nommé dans l'édition 'allégorique' et un autre nommé 'moral. Dans Aser cum pinguis, ces deux commentaires ont des styles très différents. Le commentaire allégorique regorge d'allusions aux sciences naturelles et marque une forte attention à l'hérésie cathare. Il porte la marque de fabrique de Roland de Crémone et date, sans nul doute, de son enseignement parisien en 1229-1230 ${ }^{191}$. Le commentaire moral est beaucoup plus centré sur le petit monde ecclésiastique parisien et sur l'Université. L'exégète attaque violemment les juristes et les avocats ${ }^{192}$. Et comme lavait remarqué Robert

$\overline{189}$ «Unde dico quod plura accipere quibus servire non potes, peccatum est et malum in via morum ... tamen sunt aliquid casus in quibus licet sine dispensatione ... Est alia opino que dicit quod licet habere plures, quam magis approbamus sed non sententiamus ", ed. GuYot, op. cit.

${ }^{190}$ R. Lerner, « Poverty, Preaching, and Eschatology in the Revelation Commentaries of Hugh of St Cher », dans The Bible in the Medieval World. Essays in Memory of Beryl Smalley, éd. K. Walsh et D. Wood, Oxford, 1985, p. 157-189 [Voir aussi les hypothèses de datation différentes de A. Boureau, «Bonaventure, commentateur de P'Apocalypse. Pour une nouvelle attribution de Vox domini ", Franciscan Studies, 70 (2012), p. 139-81].

${ }^{191}$ Nous ne donnerons qu'un seul exemple. Le commentateur allégorique que nous identifions comme Roland de Crémone explique sa théorie physique des tremblements de terre et utilise la comparaison de la châtaigne qui éclate dans le feu en émettant des jets de vapeur (Hugues de Saint-Cher, Postilles, Cologne, 1621, t. VII, f. 412r). Cet exemple original et qui ne provient pas de la science antique se retrouve dans la Somme de Roland de Crémone (ms. Paris, Bibl. Mazarine, f. 99r) pour avancer Pidée que la lévitation n'est pas nécessairement surnaturelle (nous devons cette référence à Maaike van der Lugt). Dans ce commentaire sur l'Apocalypse, Roland laisse déjà percevoir qu'il sera un inquisiteur rigoureux : «Hoc dicitur quia tunc heretici non comburentur, super quo arguuntur sancti illius temporis. Unde ex hoc est argumentum quod heretici sunt comburande sicut fit hodie ", ibid., f. 376r.

${ }^{192}$ Lauteur attaque les décrétistes et les légistes qui prétendent juger des âmes, ce qui n’appartient qu'au théologien : Aser cum pinguis, ad cap. 2 : «Blasphemaris ab his qui se dicunt Iudeos esse : Iste sunt decretiste qui dicunt legem et evangelium et evangelicas et ecclesiasticas institutiones docere. [...] Unde bene sequitur et non sunt $i u d e i$, id est vere confitentes sed sunt Spartiatae qui se dicunt fratres iudeorum 1 Machab. 12.6 Spartiatae interpretantur expedite illuminati et significant Decretistas qui ad hoc illuminati sunt scientia litterarum domini pape et constitutionum ecclesie ut alios expediant et ipsi aliquando magis impediunt per dilatationes falsas et exceptiones et falsas allegationes. [...] Theologi enim si bene libros sanctos tenerent in manibus id est in operibus et eos bene intelligerent; procul dubio decretistis non indigerent in ullo horum que pertinent ad consilia animarum. Unde et Decreta ex sacris libris theologiae sunt extracta. Sed hodie fit econverso quoniam non solum Decretistae sed etiam Legistae quod est abominabilius dicunt se non indigere consilio theologorum imo, quod deterius est, preferunt se illis in consiliis animarum et non attendentes, imo negligentes interiora que magis curat Deus, secundum sua statuta exteriora volunt iudicare de occultis et sic totum pervertunt ", ibid., f. 372v. Le commentateur rapporte aussi un exemplum sur Néron en enfer plongé dans un bain d'or en fusion et appelant les avocats à le rejoindre (ibid., f. 378v) 
Lerner, il est très dur contre les pluralistes ${ }^{193}$. La commentateur traite de Nicolaïtes " ceux qui ont prêché en français le vendredi " en faveur du pluralisme. Il raconte ensuite lanecdote des maîtres pluralistes qui abandonnent à larticle de la mort leurs bénéfices sauf un ${ }^{194}$. On trouve déjà des linéaments de cette histoire chez Robert de Courson mais elle ne trouve sa forme définitive que dans la question $A^{195}$.

Le commentaire moral d'Aser cum pinguis s'attaque aux têtes de Turc de la campagne de prédication de 1230-31 : les juristes et les pluralistes. Néanmoins, on n'y trouve pas d'allusion à la grève et il semble donc postérieur à celle-ci. On peut, de plus, le rapprocher d'un autre texte : le De collatione beneficiorum de Guillaume d'Auvergne. L'évêque de Paris traite dans cet opuscule principalement de la collation des bénéfices et dans la septième partie de louvrage de la pluralité. Ce qui rapproche Guillaume d'Aser cum pinguis et l'écarte des questions disputées (qui utilisent des autorités juridiques) c'est le mépris du droit. Guillaume dit dans sa préface qu'il prouvera que le pluralisme est interdit grâce aux Écritures sans laide des canons et des lois séculières ${ }^{196}$. Surtout, dans un passage de son tortueux traité, il explique que les clercs trop avides de biens matériels sont comme des chevaux et des ânes uniquement intéressés par leur picotin. Ces clercs ont des prébendes d'ânes (prebendas asinarias). Et, lévêque de Paris ajoute qu'il en a souvent parlé dans ses sermons ${ }^{197}$. Or, Aser cum pinguis utilise exactement la même métaphore filée entre le mauvais clerc pluraliste, les chevaux et les ânes ${ }^{198}$. Le dominicain qui est responsable du commentaire moral a très vraisemblablement réutilisé la prédication de Guillaume d'Auvergne. À la fin du De collatione beneficiorum, Guillaume utilise une formule dans un latin obscur qui suggère qu'il considère son traité comme un matériel préparatoire à des questions disputés et qu'il en appelle aux maîtres pour aboutir à une certitude en la matière ${ }^{199}$. Cela placerait le traité avant le début des questions disputées

${ }^{193}$ LERNER, op. cit., p. 170-71.

${ }^{194}$ Aser cum pinguis, ad cap. 2 : «Doctrinam vero Nicolaitarum : adhuc tenent in ecclesia Dei quotquot dicunt vel credunt licitum esse plures prebendas sine peccato posse haberi ab uno, sicut illi qui vulgatam venerem predicabant. [...] Veniam tibi cito : ad mortem, scilicet se vocabo quasi dicat Dominus saltem quando visitabo per mortem coactus eris dimittere que male et contra conscientiam percipies te tenuisse. Hoc est enim signum verissimum quod peccatum est, quia nullus quantumcumque fuerit contrarie opinionis sapiens dico in articulo mortis audet plures retinere sed omnes dimittit ", ibid., f. 374r.

${ }^{195}$ Robert de Courson, Summa (ms. Paris, BnF, lat. 14524, f. 74r).

${ }^{196}$ Guillaume D’Auvergne, De collatione beneficiorum « Sexto loquemur de pluritate ipsorum in una persona an sit licita, an non et quomodo non, incedentes per vias probationum cum ipsius sacri textus testimoniis, sacros canones, et leges seculares que ad hoc faciunt suis professoribus atque doctoribus suis reliquentes » Opera Omnia, Paris / Orleans, 1671, t. II, p. 248.

${ }^{197}$ «Et sicut monachos quosdam solemus dicere coquinarios aut refectarios pro eo quod corde in coquina vel refectario solummodo versantur. Sic et istos non veri nominis canonicos, sed magis horreales ut dicimus aut cellarios, et ut loquamini assertius inter veri nominis canonicos aut clericos nec clerici, nec canonici, sed magis asini vel equi habendi sunt utpote presepibus ad comedendum alligati corporaliter; non enim prebendam clericalem vel portionem spiritualium bonorum videlicet gratie et glorie vel querunt, vel diligunt, sed solas prebendas asinarias, vel equinas, que utique passiones bonorum temporalium sunt : qui nostri et asini corpora nostra sunt, de quibus in declamatoriis sermonibus multa iam diximus », ibid., p. 259.

${ }^{198}$ Aser cum pinguis, op. cit., f. $371 \mathrm{v}$ (la sexualité des clercs est comparée à celle de l'étalon qui veut monter toutes les juments) et f. $375 \mathrm{v}$ (le clerc qui accumule des bénéfices est comme un âne qui empile des fardeaux sur son postérieur, cf. LERNER, op. cit., p. 170).

${ }^{199}$ Guillaume D’Auvergne, De collatione beneficiorum : « Et hic quidem tractatus illius finem facimus materiam disputationis et vias declarande veritatis in conferendis et obtinendis beneficiis ecclesiasticis, prout desuper accepimus tradentes, et si que sunt certa hec maiora maioribus reliquentes »(Ibid., p. 259). 
en 1235 , en tout cas avant la détermination de Pévêque en 1238. Le commentaire moral d'Aser cum pinguis doit être contemporain.

\section{CEuvres influencées Par la QUerelle De I $235-38$}

Guillaume Peyrault parle longuement de la pluralité des bénéfices dans sa Somme des Vices (1236-1248) au sein de son traitement de lavarice ${ }^{200}$. Il ne semble pas avoir utilisé la question $A$. Néanmoins, parmi les raisons qui condamnent le pluralisme, il fait une allusion à Panecdote des maîtres moribonds, comme si Phistoire était devenue connue de tous ${ }^{201}$. Elle trouvera en tout cas sa forme littéraire définitive avec le récit de Thomas de Cantimpré rédigé dans les années 1250 .

\footnotetext{
${ }^{200}$ A. Dondaine, " Guillaume Peyrault : vie et œuvres ", Archivum Fratrum Praedicatorum, 18 (1948), p. 162-236.

${ }^{201}$ Guillaume Peyraud, Summa Virtutum ac Vitiorum, De beneficiorum pluritate et quod plura beneficia ecclesiastica non possint haberi : "Tertio potest idem ostendi per hoc quod in fine vite quum Dominus venturus est ad eos, non auderet retinere multitudinem beneficiorum talium. Si enim gratia Dei et amore ea possederunt, desiderare debent, ut in statu tali a Domino inveniantur, ut ab eo dignam mercedem accipiant. Et si unctio gratiae in statu sanitatis docebat eos beneficia multiplicanda esse, ipsa in statu infirmitatis cum maior est devotio, non permitteret eos de hoc dubitare. Non videtur esse consilium divinae gratie, quod aliquis in statu illo vivere audeat, in quo non audet mori », éd. Venise, 1571, t. II, p. 188.
} 